Portland State University

PDXScholar

$11-2-1992$

\title{
Communication Issues in the Management of a Multicultural Workforce
}

Deborah Margaret Sipe

Portland State University

Follow this and additional works at: https://pdxscholar.library.pdx.edu/open_access_etds

Part of the Speech and Rhetorical Studies Commons

Let us know how access to this document benefits you.

\section{Recommended Citation}

Sipe, Deborah Margaret, "Communication Issues in the Management of a Multicultural Workforce" (1992). Dissertations and Theses. Paper 4645.

https://doi.org/10.15760/etd.6529

This Thesis is brought to you for free and open access. It has been accepted for inclusion in Dissertations and Theses by an authorized administrator of PDXScholar. Please contact us if we can make this document more accessible: pdxscholar@pdx.edu. 
AN ABSTRACT OF THE THESIS OF Deborah Margaret Sipe for the Master of Science in Speech Communication presented November 2, 1992 .

Title: Communication Issues in the Management of a Multicultural Workforce

APPPROVED BY THE MEMBERS OF THE THESIS COMMITTEE:

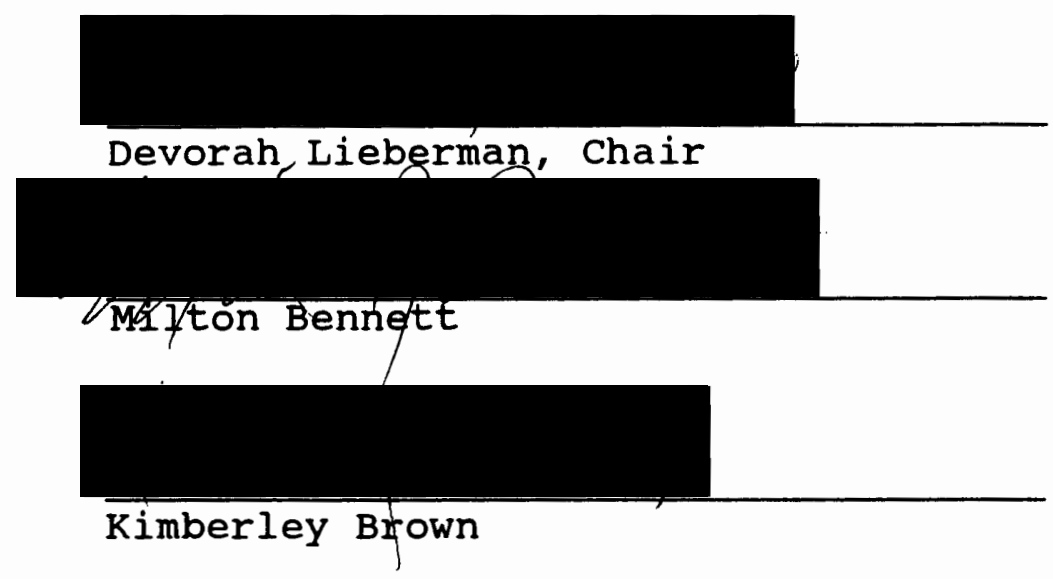

The purpose of this thesis is to examine communication issues which are most frequently identified as the concerns of U.S. managers who work with culturally and ethnically diverse workforces, and skills which are identified as useful in dealing with those issues. This thesis used a qualitative method of data collection. Information was generated through a review of literature in the fields of communication, management, and organizational behavior to determine frequently occurring themes concerning 
intercultural communication issues in the workplace. Following the review, three case study interviews were conducted with managers in the Portland metropolitan area to determine what they perceive as communication issues frequently encountered in a multicultural workforce and skills needed to effectively address these issues. Themes in the literature are compared with what the managers report are communication issues in managing a multicultural workforce.

Interview results indicated that there are both differences and similarities between what the manager reports and the literature themes. The similarities chiefly concerns the importance of nonverbal behavioral differences as a cause of intercultural communication differences. Differences between the themes in the literature and the interview results chiefly concerns the number of additional factors which could affect intercultural communication between manager and employee. More themes are suggested in the literature as sources of communication difficulty than in the interview results. These results suggest that language differences were more often the type of intercultural communication difficulties that managers encounter than is indicated by the literature. 


\title{
( COMMUNICATION ISSUES IN THE MANAGEMENT OF A MULTICULTURAL WORKFORCE'
}

by

DEBORAH MARGARET SIPE

A thesis submitted in partial fulfillment of the requirements for the degree of

\author{
MASTER OF SCIENCE \\ in \\ SPEECH COMMUNICATION
}

Portland State University

1993 
TO THE OFFICE OF GRADUATE STUDIES:

The members of the Committee approve the thesis of Deborah Margaret Sipe presented November 2, 1992 .

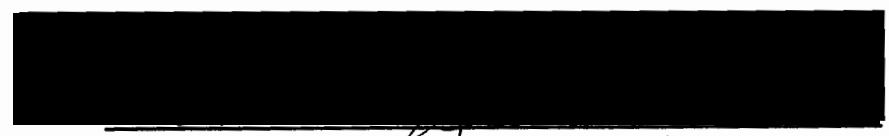

Devorah Lieberman, Chair

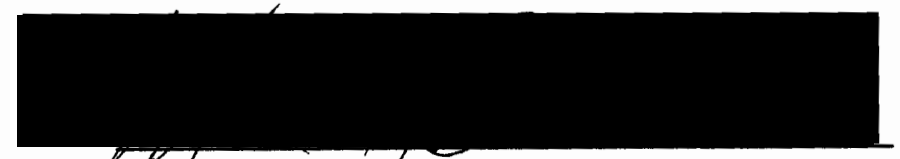

Mifton Bennett

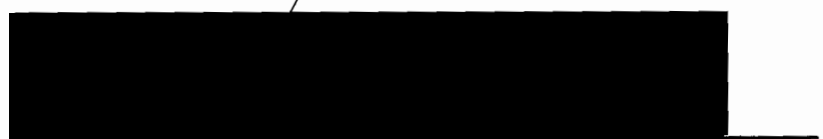

Kimberley Bfown

\section{APPROVED :}

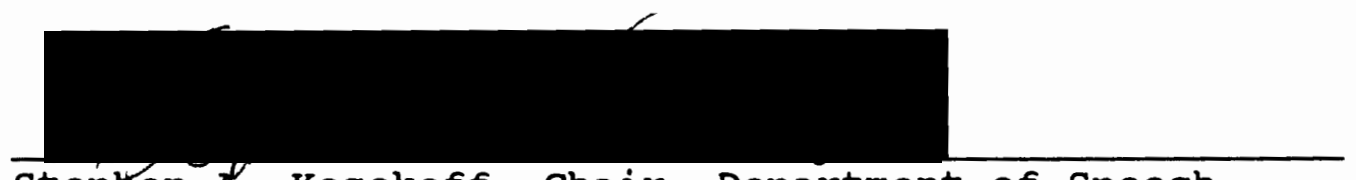

Stephen A. Kosokoff, Chair, Department of Speech communication

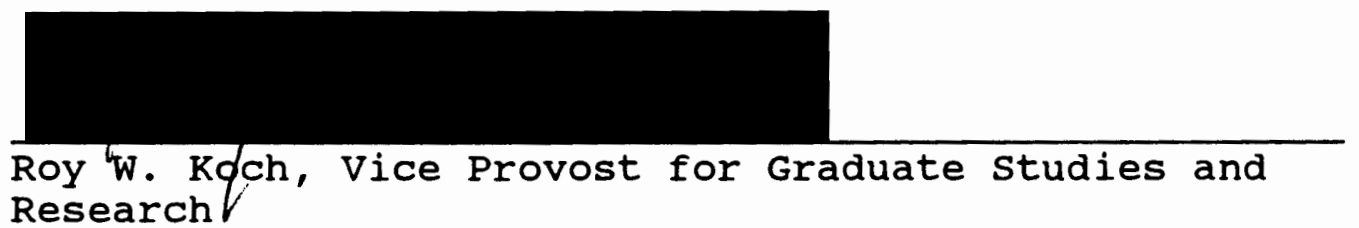




\section{DEDICATION}

I dedicate this thesis to my children, Elena May

Lani sipe and Ryan Thomas sipe. It is my hope that they will grow up to value the diversity of the human condition. 


\section{ACKNOWLEDGEMENTS}

In submitting this thesis, I wish to acknowledge the contributions of several people. First and foremost, I am very grateful to my husband Robert, for his patience, understanding, and support throughout the process of developing and completing this thesis. I am also very grateful to Dr. Devorah Lieberman for her advice, patience, support and good humor throughout the development of this thesis. A debt of gratitude is also owed to Dr. Milton Bennett for two reasons, for suggesting the initial idea for the thesis, but also for introducing me to the fascinating world of intercultural communication. Last, I am thankful to my parents for their advice, support, and interest. 
TABLE OF CONTENTS

PAGE

ACKNOWLEDGEMENTS......................

CHAPTER

I INTRODUCTION $\ldots \ldots \ldots \ldots \ldots \ldots \ldots \ldots \ldots$

Background......................

Purpose of this study............4

Plan of the Thesis..............

Significance and Justification.......6

Research Questions................

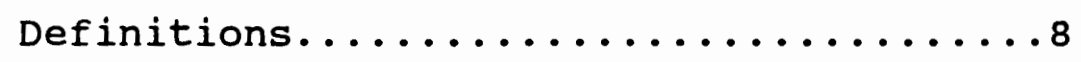

Literature Review...............

II METHODS....................... 56

Participants..................56

Procedures...................... 58

Data Analysis...............62

Manager Demographics............66

III RESULTS..................68

Employee Orientation -- Issues.......68

Employee Orientation -- Responding

Behaviors.....................71

Giving Instructions to Employees --

Issues...................72 
Giving Instructions -- Responding

Behaviors...................... 74

IV DISCUSSION....................

Limitations of the Research.........91

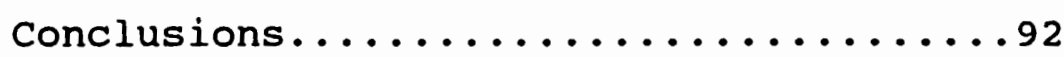

REFERENCES....................... 94 APPENDICES

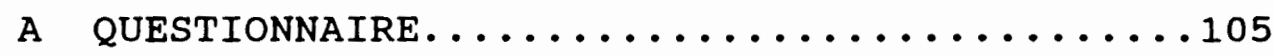

B DATA RESULTS....................... 110

C COMMUNICATION ISSUES AND EFFECTIVE

BEHAVIORS - - RESULTS OF LITERATURE SEARCH...114 


\section{CHAPTER I}

\section{INTRODUCTION}

\section{BACKGROUND}

In the last twenty years, the U.S. workforce has undergone significant demographic changes. That workforce, formerly composed primarily of white males, is now over fifty percent female and contains a mixture of races and cultures. Since 1980, the traditional majority of the American workforce, white males, has become a minority in that workforce, and, by the end of the century, will account for less than twenty percent of new entrants and less than 40 percent of the total workforce (Wall Street Journal, 1991). By the year 2000, over half of the total labor force growth will be due to the entry of African-Americans, Hispanics, and Asians into that force. Since the majority of U.S. managers are white males (Hudson Institute, 1988), there is an increasing probability that the culture of the manager will not be the same as that of his or her employees.

The above information is derived from demographic data published in the last four years by the U.S. federal government and by a report produced by the Hudson Institute (1988). In essence, this data and subsequent reports claim 
that the U.S. workforce is and will continue to become increasingly diverse, both ethnically and racially.

What do these demographic changes mean for the U.S. manager? There is a growing body of evidence which indicates that U.S. managers are encountering problems and issues in manager/employee relations not previously encountered in the traditional workforce, and that the traditional manager is not prepared to cope with these issues (Copeland, 1988). The University of Toronto's Public and community Relations office (1988) investigated how some Canadian companies were coping with cultural diversity. Managers from twelve different companies with culturally diverse workforces, representing a range of types as well as sizes of firms, were interviewed. All of the managers felt that they were unprepared for many of the challenges posed by their new, culturally diverse workforces. Some of those challenges were:

-work values and behavior which differed from those of "typical" Canadians;

-differences in appearance, dress styles, mannerisms from "typical" Canadians;

-language, both spoken and nonverbal, that was different from anything that managers and employees in Canada could understand; 
-differences in employee sources of job satisfaction or motivation;

-traditions of various types of hierarchies and rivalries which caused problems in the workplace. with increasing frequency, articles and books are appearing which maintain that U.S. managers must change in order to effectively manage this new workforce (Joynt, 1985; Wall Street Journal, 1991). Why are changes needed? Essentially, authors believe that much of what seemed to work before in terms of people management may no longer be relevant because of the change in the cultural composition of the workforce (Copeland, 1988).

Research in intercultural communication affirms that each culture has its own unique set of values, attitudes, and patterns of thinking which form the frame of reference of its members. These frames of reference also shape each individual's perceptions, behaviors, including communication style, and expectations concerning the behavior of others (Condon and Yousef, 1975; Hoopes, 1979). Consequently, people from different cultures may behave differently because of the influence of culture. Because these cultural differences are now more prevalent in the workforce, managers in the United States are often faced with different management situations and problems unlike those they experienced with a predominantly white male workforce. 
Finally, researchers (Hofstede, 1984; Adler, 1986) in the field of intercultural communication believe that how differences in culture are perceived may be related to problems in the workplace, particularly in the area of communication. This belief is due to the fact that each culture teaches its members that its way of behaving, thinking, etc., is the correct way, which implies that all others may in some way be wrong (Brislin, 1986). Since the majority of U.S. managers are white, European-American males and the workforce is increasingly composed of males and females from other ethnic groups, it follows that cultural differences regarding the "correct way" will often exist and perhaps come into conflict.

\section{PURPOSE OF THIS STUDY}

Managers must communicate with all their employees, whatever their cultural background. Consequently, when the manager and the employee come from different cultures communication is an area where intercultural difficulties are most likely to occur. What can the fields of management, communication and organizational behavior tell managers about communication issues and how to deal with those issues when the manager and the employee come from different cultures? Further, does this information 
correspond with the actual reported experience of managers in the Portland, oregon area?

This thesis addresses these questions through its twofold purpose: the primary purpose is to look at communication issues that emerge in the management of a multicultural workforce, as reported by managers themselves, and the behaviors they reported as effective in dealing with these issues. The second purpose of the thesis is to determine if these issues and behaviors were consistent with those reported in the literature drawn from the areas of management, communication and organizational behavior.

\section{PLAN OF THE THESIS}

The remaining sections of this chapter 1 ) review literature from the fields of communication, management and organizational behavior relevant to the identification of communication issues which may exist in the management of a multicultural workforce, and 2) discuss the need for further research which prompted this thesis. Chapter II discusses the method employed to determine manager perceptions, subjects, procedures, questionnaires, and data analysis. Chapter III discusses the results of the data. The final chapter, Chapter IV, discusses the themes that the managers reported and compares them to the emergent themes in the literature review. 


\section{SIGNIFICANCE AND JUSTIFICATION}

A considerable amount of research has been done on how culture and communication relate. However, most of this research has been done in the context of Americans working outside of the U.S. or in terms of international student exchange situations (Americans students living abroad or international students living in the U.S.). Research on the influence of culture in the workplace is still relatively limited and most of it suggests changes in interpersonal and organizational behavior, rather than identifying specific types of issues which may occur when different cultures coexist in the workplace.

Few works as yet exist which draw upon the fields of management, communication, and organizational behavior to describe appropriate ways to manage a multicultural workforce. In the field of management, some works have appeared in recent years which specifically address the management of a culturally mixed workforce (Harris and Moran, 1979), but no management theory has emerged which specifically addresses that type of management situation. However, the area of situational management is suggested as appropriate (Adler, 1986) for the management of a multicultural workforce. Situational management was not developed specifically to respond to a changing workforce, rather it has been suggested to be applicable to situations 
where a number of factors are undergoing change at the same time (Fiedler, 1964). Those works that discuss the management of a multicultural workforce generally suggest that managers and organizations need to "value diversity" or see value in the differences that are presented by a culturally mixed workforce (Thomas, 1991).

The area of cross-cultural management, which focuses on the management of foreign nationals, has yielded some useful insights, to be described in later pages. Finally, the field of organizational behavior has begun to address communication issues raised by the presence of a culturally mixed or diverse workforce (Mondy, 1989). Within that field, research on corporate cultures suggests some factors which relate to communicative behaviors (Schein, 1985).

Very little research exists which combines an identification from the literature of communication issues in the multicultural workplace, sources of those issues, and suggested behaviors, with research based on actual interviews with managers. Do the managers experience what the literature suggests as issues in communication in the multicultural workplace? To answer this question and to address this information gap in the literature, this thesis asks three research questions: 
1. What do managers report as communication issues in the management of a multicultural workforce?

2. What do managers report as effective behaviors in addressing those issues?

3. How do the reports of the managers compare to to communication issues and effective behaviors discussed in communication, organizational behavior and management research?

By examining the input of practicing multicultural managers, this thesis attempts to provide a greater understanding of some of the intercultural communication issues faced by managers today and their approaches to dealing with those issues. Further, by comparing this input from managers with factors suggested in the literature as communication issues and appropriate responding behaviors, this thesis attempts to highlight possible similarities and differences between research and practice.

\section{DEFINITIONS}

For the purposes of this thesis, the following definitions will be used:

Intercultural communication - the communication which occurs between two people from different cultures. Cross-cultural communication - the comparison of communication practices and behaviors in different cultures. 
Effective communication - the sending of a message from a source to a receiver with the least possible loss of meaning (Hoopes, 1979).

Manager - person in an organization charged with planning, organizing and controlling resources in order to achieve organizational goals. These responsibilities also include leading and directing people (Kallaus and Keeling, 1983). Minority - a identifiable group of people that comprise less than half of the population (Guide to American Law, 1984). Multicultural or Diverse Workforce - workforce which is comprised of at least a ten percent minority population. Multicultural Manager - person whose responsibility is the management of an ethnically or culturally diverse workforce (Casse, 1980).

\section{LITERATURE REVIEW}

\section{overview}

The following pages contain a review of literature in the fields of organizational behavior, management, and communication it relates to communication issues in the management of a multicultural workforce. This review will consider themes regarding communication issues as suggested by the literature, factors related to those issues, and 
behaviors suggested by the literature as effective in addressing the communication issues presented.

\section{Organizational Behavior}

Research in the field of organizational behavior presents information concerning issues which arise in the management of a multicultural workforce. Authors in the field of organizational behavior discuss the existence of an organizational or corporate culture (Deal and Kennedy, 1982; Hofstede, 1980). A corporate culture usually includes a system of shared values, beliefs and habits within an organization which influences behavior (Mondy, 1989). Myths, heroes, symbols and rituals may be a part of the corporate culture (Deal and Kennedy, 1982). The organizational culture has an important influence on the behavior of the organization's members. The culture reflects attitudes about what is important, how the organization works, and how employees are to behave (Copeland, 1988).

How does organizational culture affect the communication between manager and employee in the multicultural setting? As with cultures found in society at large, organizational cultures are based on certain values. Values provide the tacit mental and emotional guidelines that all managers and employees will follow and support when formulating and implementing strategy; they lay the 
foundation by which people can better relate to one another, yet they create a unique sense of identity from other companies (Deal and Kennedy, 1982).

These values (such as assumptions about human nature), are influenced to a significant extent by the values held by the host culture (Hofstede, 1984) and are elaborated upon in the corporate culture (Schein, 1985). These host culture and organizational culture values are reflected in the behavior of the organization's members.

What are some of the values of the American corporation? They include competition as a primary means for motivating employees, and stress individualism and productivity (Joynt, 1985). These values are reflective of male, white, European-based values and may differ significantly from those experienced or held by employees from other cultures (Copeland, 1988).

According to the research, the organizational culture is an environmental aspect of the context in which the manager-employee communication takes place. This culture influences the communication process (Laurent from Adler; England, Negandhi and Wilpert, 1979). When managers and employee interact, the manager's approach to dealing with that employee is influenced by the organization's overall style and approach. Both manager and employee are 
influenced by the norms of the organizational culture concerning the proper ways of interaction (Schein, 1985).

How are these values and norms passed on to the organization's members? A number of mechanisms are used; the rituals and symbols mentioned earlier are two such ways, including rituals for accomplishing specific job tasks (Deal and Kennedy, 1982). An important point is that although the rules and norms governing behavior should be explicit they frequently are not, but are unwritten and sometimes ambiguous. They may even contradict written organizational policy (Copeland, 1988). These latter rules and norms may be clear to some of the organizational members, but often are not to women and minorities, who may be more familiar with somewhat different norms.

Organizations may initially pass on these values by selecting candidates who resemble present members in style, assumptions and beliefs, and perpetuate the values through rewards, promotions and punishments (Schein, 1985). These values can also be passed on through the behavior of the manager; by what he or she pays attention to, how the leader reacts to critical situations, and through deliberate role modeling (Schein, 1985). Some authors believe that the passing on of corporate values is a key managerial responsibility (Deal and Kennedy, 1982). Other aspects of the corporate culture which he or she can pass on include 1) 
language standards, 2) public decorum, and 3) standards regarding interpersonal behavior (Deal and Kennedy, 1982).

Because of differences in host cultures and resulting differences in organizational cultures, concepts of appropriate leader-subordinate behavior will also vary (Mead, 1978; Hofstede, 1984). Thus concepts will be influenced not only by the host culture, but also by the corporate culture. The influence of the organizational culture as well as the host culture is of central importance to the communication situation between manager and employee because it suggests one possible source of intercultural communication difficulty.

\section{Management}

This thesis concerns the management of a multicultural workforce. Management texts commonly define "management process" as consisting of four main functions: planning, organizing, influencing and controlling (Mondy, 1989; Harris and Moran, 1979). Harris and Moran (1979) define the process as being the coordination of human and nonhuman resources in order to accomplish the objectives of the organization. They also describe the influencing function as including leading, communicating, problem-solving, relating, decision-making, conflict managing, negotiating, controlling, training, evaluating and innovating activities. 
For the purpose of this thesis, the primary functions of a manager are planning, organizing, controlling resources, and leading people to reach organizational goals (Kallaus and Keeling, 1983). This definition emphasizes the aspect of management which involves working with people.

Leadership is that aspect of management which most involves communicating with individuals. Leadership is seen by a number of authors as the exercise of interpersonal influence through the process of communication toward the attainment of a specified goal or goals (Tannebaum, 1961). Any manager, then, has as one of his or her managerial responsibilities the influencing of the behavior of the people he or she supervises; this influencing is accomplished through communication.

A manager influences, leads, and directs individuals when selecting and orienting the staff, and in supervising, motivating, training, and evaluating it (Kallaus and Keeling, 1983). The more specific people-related tasks of a manager include selecting, rewarding, problem-solving, decision-making, conflict management, negotiating, training, evaluating, innovating, and supervising. Much of a manager's communication with people involves providing information to them. For example, a manager must give employees specific job instructions, information about organizational procedures and practices, about the rationale 
of the job, and about their job performance (Kallaus and Keeling, 1983). Finally, a manager must also communicate with superiors to discuss such things as problems and processes. Yet managers also use communication for a different purpose. Most managers accomplish their goals largely by managing relationships; he or she usually relies on the support, cooperation, or approval of a large number of people to accomplish those goals (Uterhoeven, 1990).

As a result of the nature of managerial responsibilities, research suggests that managers spend approximately 75 percent of their time communicating (Mondy, 1989). In order to effectively accomplish management tasks, good communication skills are necessary (Kallaus and Keeling; Klatt, Murdick and Schuster, 1978). These skills are identified in basic texts on management and are confirmed in research on interpersonal communication (Klatt, Murdick, and Schuster, 1978). Communication skills frequently identified (Tortoriello, Blatt, and De Wine, 1978; Klatt, Murdick, and Schuster, 1978) as necessary for the effective manager to possess include:

- the ability to listen effectively

- the ability to give appropriate feedback

- a sense of empathy

- the ability to paraphrase 
- sensitivity to the feelings and ego-defense needs of subordinates

A sense of flexibility to changing and different situations is also often mentioned (Odiorne, 1987). The same author asserts that a basic understanding of human behavior and a respect for different values are also necessary. All of the above skills and behaviors are related to the concept of effective communication. They are also seen by some authors as necessary to impart a sense of motivation to the employee (Mondy, 1989).

Each manager develops his/her own particular managerial and leadership style (Luthens, 1985). This style is influenced by a number of factors: the culture of the organization (Mondy, 1989), the situation, the manager's personality, training, and his/her own interpersonal behavioral skills (Bass, 1981). A manager's style is also influenced by a basic conceptn of his or her role. For example, a manager might choose whether to be a problem solver or an expert (Adler, 1986). All of these factors influencing managerial style also have a direct influence on the pattern of a manager's communication (Tortoriello, 1978) .

Some managers receive specific training in how to lead and manage a workforce. Often this training is obtained through attendance in courses at U.S. colleges and 
universities. The topics of leadership and management theory have been taught in U.S. college programs for over thirty years. Three basic approaches to leadership theory have been taught: the classical approach, the systems approach and the behavioral approach. The concepts which are the foundation of leadership theory are also related to concepts concerning worker motivation. All of these approaches and the concept of management itself originated in the United States (Hofstede, 1984) and are predicated on situations found in the traditional U.S. workforce.

Recent management texts have generally recommended that the manager be flexible in choice of leadership styles and use the one most appropriate to the situation (Odiorne, 1987). Adapted from the theory of Fiedler, this approach, referred to as situational management, recommends that the manager vary his/her style according to his or her personality, the task to be performed, the employees involved, and the environment in which the manager and employees are operating. Situational management is perhaps the most widely touted management theory in practice today. Thus far, this thesis has addressed the functions of all managers and the importance of communication in carrying out those functions. Are there additional variables present in the management of a multicultural workforce that require a manager to perform additional functions or have additional 
skills? A host of issues seem to arise in the diverse workforce situation that do not appear when the workforce is relatively homogeneous, suggesting that additional elements need to be considered. Managers report difficulties in communication with their minority employees, in understanding what motivates them, of conflict in the workplace (University of Toronto, 1988; Wall Street Journal, 1990; Tortoriello, 1978). All of these situations can be detrimental to production and the reaching of organizational goals (Luthens, 1985).

In order to investigate factors which may be related to the emergence of these situations in the multicultural workplace, this researcher examined information from the field of cross-cultural management, also referred to as comparative management. The area of cross-cultural management has largely evolved in the last twenty years. Cross-cultural management explores how people behave in organizations and trains people to work with employee and client populations from differing cultures (Adler, 1986). It is valuable to look at research in this field for two reasons: 1) cross-cultural management's premise is that the cultural environment in which a manager operates influences management behavior and 2) cross-cultural management assumes that different cultural groups require 
different styles of management. These two concepts will be further developed in the following pages.

Cross-cultural management relies on the findings of intercultural communication that culture influences behavior and, since cultures can differ in several ways from one another, so can behaviors. Therefore, a dominant issue in this field is the impact of culture on management (Joynt, 1985) .

There is as yet no definite agreement that management is strongly culture bound; some researchers maintain that there are universal principles that can be applied to all management situations (Laurent, 1983). The majority of authors however, seem to agree that culture influences managerial behavior in some way (Laurent, 1983). Crosscultural management theory further asserts that differences exist across cultures in management practices. These differences has been studied by several authors and the studies have involved the comparison of a number of cultures (Laurent, Hofstede, 1984; Kume, 1985). For example, one way in which managerial style is exhibited is through the style of decision-making adopted by the manager. Research indicates that decision-making styles, like other behaviors, differ across cultural lines (Stewart, 1972). An example of difference in supervisory style is described by Kras (1988) who found that in Mexico, managers are only beginning to 
delegate responsibility and subordinates are used to being assigned tasks, but no authority; U.S. managers, on the other hand, generally delegate responsibility and authority. She also argues that Mexican managers are basically theoretically minded and have difficulty with practical implementation of theory, while U.S. managers are basically pragmatic and action-oriented.

Researchers suggest, then, that the participative management style, for example, which is the prevalent one being espoused in U.S. management today, is not necessarily the most appropriate one (Joynt, 1985) for the management of a multicultural workforce. One can reason that employees in U.S. companies who are recent immigrants will not necessarily respond well to the participative style if it differs from one to which they are accustomed.

with regard to leadership, cross-cultural management or leadership theory begins from the same premise as conventional management theory, that the foundation of leadership involves the ability to influence the thinking, attitudes, and behavior of people (Adler, 1986). However, it goes beyond that; it assumes that cross-cultural managers must adapt their style of leadership to the culture of the employees (Adler, 1986; Hofstede, 1984). Thus, traditional U.S. management theories may not be appropriate to the management of a diverse workforce. 
cross-cultural management also looks at the way managers in different cultures perceive the managerial role and functions. For example, most U.S managers see the role of the manager as being a problem solver; managers should help subordinates discover ways to solve problems. The French attitude, however, is generally that the manager should be an expert (Adler, 1986). Regarding this issue, Laurent's (1983) findings reveal a wide gap in conceptions of management between the Latin-influenced countries of France, Belgium and Italy and the Nordic cluster of America and sweden. One conclusion is that although leadership may have similar functions across cultures, the behaviors exhibited to accomplish those functions, including style, and the perception that the manager may have of his/her role may differ across cultures.

Cross-cultural management tells us that managers' perceptions of their roles may differ across cultures; it also presents information about employee perceptions of the role of the manager. A behavioral approach investigated by Hui (1990) described leader behaviors along the two dimensions of person orientation and product orientation. His review of data from both Western studies and Eastern studies indicates that employees in many cultures prefer a manager or leader who is both person-oriented and taskoriented. Yet other research indicates that every culture 
has its own expectations and assumptions as to the appropriate behavior for a manager and an employee to act, and these expectations and assumptions differ across cultures (Griggs and Copeland, 1985; Kras, 1988).

Thus, research in management describes the many types of situation requiring communicative interaction with employees. Research in cross-cultural management suggests possible differences cross-culturally concerning appropriate managerial behaviors and practices, thus suggesting some of the issues and sources of those issues which are found in the multicultural workplace today. Research in communication describes more specifically the factors present in the communicative process and suggests some areas of potential communicative difficulty in the workplace.

\section{Communication}

It is clear from the literature that communication is an important part of the manager's role and is central to the functioning of an organization (Luthens, 1985), and that it provides the means by which the objectives of the organization can be reached (Kallaus and Keeling, 1983). It also makes possible cooperation and action (Harris and Moran, 1979).

Researchers also tell us important information about the effect on the organization of poor communication, a subject of concern for managers of multicultural workforces 
who experience difficulties in communicating with their employees. Poor communication can cause tensions, anxieties, and frustrations that can have a dramatic effect upon the general organizational atmosphere and organizational productivity (Tortoriello et al, 1978). since communication is a central focus in this thesis, it is helpful to review what happens in the communication process in order to more specifically identify communication issues which may arise in the multicultural workplace.

A common definition of communication is that it is the exchange of meaning (Barnlund,1981; Adler, 1986; Ronen, 1986). Meaning and understanding must be shared by both parties before it can be said that accurate communication has taken place. Condon and Yousef (1975), in discussing communication, stress that communication is an interactional process. In a similar vein, other authors describe communication as a dynamic, on-going process; that it changes and is reciprocal (Tortoriello, 1978; Harris and Moran, 1979). Other authors remind us that communication occurs in a context (Harris and Moran, 1979) and that it involves, through the message, the transfer of information, which can include feelings as well as ideas (Mondy, 1989). When each individual comes to a communication situation, he or she brings to it a set of values, beliefs, attitudes, perceptions of the situation, and expectations 
about the behavior of others (Sitaram and Haapanen, 1979). Perception is the understanding or view people have of things in the world around them (Mondy, 1989). Research in the field of communication indicates that each person views the world not as objective reality, but sees it through a series of filters. These filters are perceptual sets or ways of interpreting what the individual sees. They are also ways of selecting from the vast array of incoming stimuli, what is more important or less important information. Finally, these sets are also used to organize information.

The difficulty for effective communication is that sets of perceptions or constructs are unique to the individual. They are unique because the life experiences of each individual, which determine meaning, are unique. Moreover, each person is generally unaware that his or her perceptions are not shared by others. Two people can receive the same message and derive from it two entirely different meanings (Harris and Moran, 1979). With these differences in meanings, it becomes difficult to share the same meaning and thus to communicate. This is due in part to the fact that we tend to ignore or avoid information which is inconsistent with our view of ourselves or others (Klatt, Murdick and Schuster, 1978). 
A host of additional variables can affect the communication process, including language used and language skill, perceptual differences, thought patterns or forms of reasoning, roles and expectations concerning role behavior, each individual's self concept, rules of communication, images of the other, and nonverbal communication (Harris and Moran, 1979). Effective communication attempts to bridge these differences so that meanings are shared. If they are not, a communication breakdown is likely to occur (Mondy, 1989).

The research of Roberts (1971) suggests another set of factors which may affect communication. After reviewing the existing literature on communication in an organization, Donald Roberts concluded that the flow of information can affect receivers in the following ways:

- People are more open to messages which are consistent with their existing images, beliefs, and values

- Messages which are incongruent with values tend to engender more resistance than messages which are incongruent with rational logic. These observations have direct relevance to the intercultural situation which occurs between a mainstream American manager and an employee from another culture because the observations suggest that the introduction of 
differences into a communication situation will engender resistance and defensive attitudes, both of which are barriers to communication.

The potential difficulty of communication in the multicultural workforce can be understood more fully by looking at the communication process from the "rulegoverned" perspective. The basic concept in this perspective is that social behavior is structured and organized and rules are considered to be the mechanism through which social action is organized (Littlejohn, 1983). Thus, for communication to take place, two or more interacting individuals must share rules for using symbols. Not only must they have rules for individual symbols, but they must also agree on rules regarding the conversational process, such as turntaking, courtesies, etc. (Shimanoff, 1980). Some of these rules are explicit but most are implicit, and must be inferred from the behavior of the participants.

One of the theories developed from the rules perspective is referred as the coordinated management of meaning. According to the theory, one of the primary tasks in all communication is to develop some sort of coordination through agreement by the participants in the communication on a common set of interactional rules. This process must take place before mutual understanding can occur (Pearce and 
Cronen, 1980). When individuals are faced with behaviors that seem inappropriate or incomprehensible and for which they are unsure as to the appropriate response, a tension ensues. This tension is referred to as high anxiety or communicative apprehension (Barna, 1982).

The rules approach is relevant when the communication between manager and employee is intercultural. The approach suggests that in any communication situation, when any two people come together, neither initially knows precisely which rules the other person will consider important (Pearce and cronen, 1980). Since we know from the literature that culture influences behaviors and norms, a manager and an employee coming from different cultures may approach a communication situation with different sets of rules and not be aware of it. The behaviors of each may also seem inappropriate. The resulting tension, or communicative apprehension, has been indentified as a source of communication difficulties between cultures (Barna, 1982).

The existence of differences in rules and perceptions thus presents a potential barrier to communication. As allued to in the section on management, interpersonal communication research has focused on behaviors and skills which can improve communication. These skills are relevant to the intercultural situation, where the meanings and perceptions are more likely to be quite different from one 
another than in a situation where the communicators share the same culture. Those skills which are most frequently described are listening, using feedback, and paraphrasing. The use of these skills will be further discussed from an intercultural perspective in the following sections.

\section{Intercultural Communication}

One of the primary centers of intercultural communication today is the workplace. Yet until very recently, literature regarding this topic was scarce (Asante and Davis, 1989). However, it is helpful to examine research in the field of intercultural communication in general in light of what it may be able to tell us about intercultural communication in the workplace. This section will briefly examine many of the ways that culture influences communication, particularly the ways in which cultural differences may lead to difficulties in communication.

Intercultural communication addresses communication between people of different cultures, as opposed to nations; it addresses the communication which occurs when the message producer and the message receiver are from two different cultures (Samovar and Porter, 1982). Intercultural communication begins from the same premise as do many theories concerning communication; that our communicative behaviors are the results of our relationships, heritage and 
status perceptions (Asante and Barnes, 1979). Since these elements each differ according to the individual, different persons are Iikely to impose different structures on the same communication process (Condon and Yousef, 1975). These differences are strongly influenced by the cultural background of each individual.

Researchers believe that communication and culture are inextricably bound (England, Negandhi and Wilpert, 1979; Condon and Yousef, 1975). Culture influences who we talk to and what we talk about. Thus, when cultures vary, communication practices also vary (Samovar, 1981, Joynt, 1985; Ronen, 1986).

In essence, the theoretical paradigm of intercultural communication is that differences exist between cultures and these differences affect the communication between people coming from different cultures. Intercultural communication has focused on differences in culture as the primary source of differences in communication. Before examining the forms those differences take, it is useful to examine what is meant by "culture" and in what ways it influences communication behavior.

Culture is essentially the way of life of a group of people; the patterns or general tendencies according to which they think and behave (Stewart, 1972). Most authors generally agree that culture includes widely shared ideals, 
values, formation and uses of categories, assumption about Iife, and goal-directed activities. All of these areas become unconsciously accepted as "right" and "correct" by people who identify themselves as members of a society (Brislin, 1990).

Culture also provides a system of socially created and learned standards for perceiving and acting (Nadler, Nadler and Broome, 1985). These standards help us solve external and internal problems of behavior, such as how to communicate with each other and how to survive in the environment. They also function to reduce the anxiety that humans experience when they are faced with cognitive uncertainty or overload (Schein, 1985). Basically, culture provides us with a guide as to how to act in any situation.

An important theme in intercultural communication concerns the influence of culture on perception. As discussed in the section on communication, research indicates that when an individual perceives the world around him, he does so selectively, resulting in an interpretation of reality. Culture plays a central role in the selection process because it helps to shape the "set of glasses" or constructs through which an individual can look at his world (Barnlund, 1981). These constructs also influence what a person anticipates in terms of behavior and how she or he interprets the behavior of others (Nemetz-Robinson, 1985). 
Since each culture's world experience is different, the constructs used by individuals from different cultures for perceiving the world will be different. As differences in cultures are more extreme, the perceptions of individuals from different cultures may more markedly differ when observing the same situation. Similarly, their subsequent reactions to the situation are also culturally influenced and may differ across cultures.

Another important theme in intercultural communication is that the very patterns according to which an individual thinks are influenced by the culture from which $s /$ he comes. Several authors (Kume, 1985; Stewart, 1972; Althen, 1988) have identified three main patterns of thinking which cultures may exhibit: inductive, deductive and relational. The inductive approach moves from facts to a theory which systematizes the facts. The deductive approach moves from general theory and fits the facts into it. The relational approach rests on experience, using analogies and metaphors in drawing conclusions (stewart, 1972). This latter approach is the one commonly found in chinese styles of thinking, while the inductive approach is most typical in mainstream American thought patterns.

These different patterns of thinking can have significant ramifications in the workplace, particularly in the areas of problem-solving, planning and decision-making. 
Stewart (1972) suggests that U.S. organizations must be aware of these differences when working with individuals or groups from other cultures. When attempting to solve a problem, for example, European Americans will most likely take a "what are the facts" or inductive approach and attempt to develop a theory or system for looking at the facts. Possible decisions are developed through anticipation of the consequences of alternative courses of action (stewart, 1972) In contrast, a person using the relational approach will try to compare these events or facts to past experience in an attempt to construct a framework for viewing them. To solve a problem and/or make a decision, the relational thinker is likely to seek solutions from past experience. A deductive thinker will attempt to see an overall pattern or develop a theory, then determine which factors do or do not fit.

Different patterns of thinking can also affect the way in which problems are presented. The U.S. inductive, linear pattern tends to foster a step-by-step "get to the point" style of presentation and argumentation (stewart, 1972). The relational pattern encourages metaphorical argument and a circular approach that does not specifically name the problem, with the assumption that the listener will "get it". The deductive pattern focuses on analysis, seeking the underlying factors that created the current situation. 
The determination of who is involved in the decision process may also differ. The European American tendency is to use a participative democratic style. In Japan, the dominant approach is to build a consensus, whereas many Arab and African cultures will use a consultative approach, consulting with senior or respected members of the community before making a decision (Copeland and Griggs, 1985).

Consequently, when a manager and employer come together to solve a problem, they may be employing different patterns of thinking or approaches when looking at the problem. They may also be calling upon different styles for constructing a solution and making a decision (Ramsey, 1979). Neither person may be aware of these differences. The communicative result is that each may believe the other person "just doesn't understand" and isn't "making sense" (Althen, 1988).

A complicating factor is that the employee will often not be communicating in his or her native language and be unaware of the precise meaning of a word or phrase in the second language. Additionally, a concept may not be easily translatable from one language to another. The possible differences in meaning will have an impact on communicative interaction.

Another factor influencing the content of the communication concerns language itself. Many researchers theorize that language is influential in shaping culture, 
and therefore cultural constructs (Whorf, 1954). Accordingly, a person's constructs for viewing life and assigning meaning are limited by his/her language. In essence, the language helps to shape an individual's reality. A person moving from one language to another might therefore have difficulty in understanding or giving the correct meaning to a concept with which he's not familiar.

Several potential barriers to intercultural communication in the workplace have so far been identified in the literature on intercultural communication: differences in perception, in the assignment of meaning, in patterns of thinking, and in styles of decisionmaking. An additional barrier suggested in the literature (Barna, 1982) is that of projected cognitive similarity - the manager might assume that the employee perceives the situation or attaches the same meaning to a word as the manager when in fact, perceptions and meanings differ.

Values. In their approach to studying culture, Kluckhohn and Strodtbeck (1961) suggest that each individual must deal with a certain number of universal questions: What is the nature of reality and truth, the nature of human nature, the supernatural, the nature of human activity and the nature of human relationships? Cultures develop in part as a way to answer these questions. Cultures differ from one another in that they provide different answers. 
A culture's basic attitudes concerning each of these universal questions is manifested in the values and beliefs that it promotes in its members. These values and beliefs are exhibited through cultural norms (Schein, 1985). These norms influence both verbal and nonverbal behavior in that they provide guidelines about the proper way for individuals to relate to one another. Some authors see the variable of values as the most important in intercultural communication because 1) when they are different, individuals tend to use their own values to judge others; 2 ) differences in values can cause misunderstanding (Knotts, 1989), communication gaps and even no communication (Sitaram and Haapanen, 1979); and 3) values underlie all human behaviors. Knowledge of an individual's basic cultural values will yield a more profound understanding of what determines that individual's behavior than can be gained by learning specific nonverbal behavior differences between cultures (Ronen, 1986). Examining possible value differences across cultures can thus give us some useful information about potential intercultural communication problems in the workplace.

One value orientation in which mainstream American culture differs greatly from many other cultures concerns the identity of the individual. Mainstream U.S. culture is seen by many authors (Condon and Yousef, 1975; Knotts, 1989; Stewart, 1972) as being individualistic and stressing the 
importance of the individual establishing his/her own identity. This orientation values competition and fosters the rights of the individual. In contrast, many other cultures see the individual as deriving his/her identity from his/her relations with other people. This orientation values cooperation and the maintenance of social harmony (Schein, 1985) over individual recognition and rights. Cultures valuing social harmony may view competitiveness and individual recognition as undesirable (Knotts, 1989). As a result of cultural difference regarding this value, misunderstanding, tension, or a lack of understanding may occur in the workplace when a manager from one culture encourages competition or recognizes individual achievement by a person whose culture values cooperation and group achievement.

Individuals in a culture may value the maintenance of social harmony more highly than honesty. Preventing social embarassment for another person helps to maintain that harmony. To avoid such embarassment, an individual from a culture valuing social harmony is often unwilling to refuse or deny a request by another, or to say "no". Further, the answer to a question may indicate the respondent's intention rather than the actual situation, in part due to a wish not to disappoint the other person. 
In contrast, mainstream U.S. individuals believe that 'honesty is the best policy'; telling the truth should be of primary importance (Copeland and Griggs, 1985). Consequently, a mainstream U.S. manager is likely to expect an honest answer from an employee, even if it may create a problem or some difficulty. If the employee's culture values harmony over honesty, he or she is likely to respond in a way which would provide or maintain harmony in the relationship. Neither might know of these differences in values. The opportunity thus exists for communication breakdowns.

Many European Americans differ from individuals in other cultures concerning their views regarding the individual's relationship with nature, specifically in terms of humans being able to affect their fate. One aspect of European American culture is a belief that one can control, to some degree, one's own fate; people who passively acceptable undesirable conditions are seen negatively (Althen, 1988). However, many other cultures see human nature as unable to change nature or affect events; whatever happens was intended to happen and a person cannot significantly change events. As a result of these extreme differences in orientations, the concept of planning, which is a popular activity in many U.S. organizations, may make little sense or has limited value in organizations in other 
cultures (Stewart, 1972). On an individual basis, this difference in orientation affects how problems are viewed from one culture to another. Should one try to overcome them, or accept them as inevitable? Differences in views concerning the ability to influence the future contains the seeds for intercultural communication difficulties.

The values of a culture have a significant bearing on the behaviors an individual will exhibit, including the style in which one communicates with others, yet most people-including most mainstream Americans-are unaware of their communicative style (Althen, 1988). Elements of communicative style include circular or linear conversation, subtlety or directness, and the use of greeting rituals (Bennett and Bennett, 1992). As with differences in meaning, differences in communicative style can cause serious problems in intercultural interactions, including tension, misjudgments, and misinterpretations (Althen).

Attribution. In addition to culture's effect on the concept of meaning, values and communicative style, many authors believe that culture affects the process of attribution (Schein, 1985). When we interact with another person, we routinely consider the causes of the other's behavior; what is the reason or motive for a particular act? We assign or attribute meaning to their actions. our subsequent feelings and behaviors will be influenced by 
these judgments (Tortoriello et al, 1978). Research indicates that people tend to attribute others' actions to their personalities or dispositions whereas they attribute their own behavior to external factors (Triandis, 1977). There is evidence that this bias is exaggerated when there are cultural differences between the individual and the person with whom they are interacting (Ehrenhaus, 1983). At the same time, each individual in the intercultural encounter may consider different features of the interaction as salient. These features in turn are interpreted in terms of the individual's cultural framework (Tortoriello et al, 1978). In short, depending upon the culture, individuals will see different behaviors as important during communication. They will also tend to attribute these behaviors to the other's personality. These differences have the potential for leading to intercultural difficulties in communication in the workplace as well as other settings. One concept that has been described by several authors as being culturally derived concerns in-groups and outgroups. One of the functions of culture is to serve as a guide to the "right" way for a person to behave in his or her culture. As a result of this training, an individual is likely to consider any other behavior as wrong (Adler, 1986; Brislin, 1986). When we couple this behavior with different (from our own) physical appearance or accents, we 
immediately place such people into the category "they", distinguishing "them" from "us" (Bochner, 1982). This concept of separateness can also be the source of intercultural miscommunication.

A concept related both to the use of categorization through the assignment of meaning and to attribution is that of stereotyping. Stereotyping is a form of categorization in which we assign characteristics we have usually observed or heard about concerning one person to a whole group of people who might be of the same race or culture (Samovar and Porter, 1981). Stereotyping is usually the result of limited or no actual experience with representatives of that group. Stereotyping can be a source of communication difficulties because it encourages the perceiver to make judgments about the other person which are not based upon the events in the actual communication situation, but upon previously formed opinions and categories; the receiver judges the source, not the message (Samovar and Porter, 1981). Its similarity to attribution is that it separates "us" from "them." By extension, prejudice can also interfere with communication. Whereas stereotyping is making a preassessment about an individual, prejudice involves the acting out of behaviors or feelings based on the stereotyping (Samovar and Porter, 1981). Thus, stereotyping encourages one to act toward the other as if 
they were an abstraction or an idea, rather than an individual (Samovar and Porter, 1981).

It is very easy to develop stereotypes about other cultures or races, since it is not possible to experience all or even most cultures during one's lifetime. Thus, stereotyping and prejudice are real possibilities in the workplace; the manager may enter a communication encounter with a minority employee having had little previous experience with someone from that cultural group, yet will probably have some image or perception of the culture (either negative or positive) based on information from other sources. The manager may begin the encounter with that image and interpret the employee's behavior according to whether it fits within that image. The manager has thus judged the source before accepting the message creating the possibility for intercultural difficulty.

Nonverbal Behavior. It has been established that differences in values and patterns of thinking can create communication barriers. Differences between cultures can also exist concerning nonverbal behavior; the use of the voice, gestures, posture, and space (Joynt, 1985).

Nonverbal communication is an element present in any communicative interaction. Many researchers (Condon and Yousef, 1975; Samovar and Porter, 1982) see it as playing a highly important role in the interaction, perhaps more 
important than the actual words. Nonverbal activity helps to establish emotional and attitudinal undercurrents in interactions; it also helps to define the nature of the relationship between the individuals (Kim, 1988). Examining the topic of nonverbal behavior helps us understand more completely what transpires in the communication between manager and employee when they come from different cultures (Ramsey, 1979) and suggests why some communication problems may occur (Copeland and Griggs, 1985; Wall Street Journal, 1990)

How does nonverbal behavior affect communication? Each culture prescribes certain behaviors for certain types of situations, such as the use of eye movement to manage conversations and to regulate interactions, and the appropriate time and place to use these behaviors. These behaviors are internalized as codes at an early age to help each of us function as a member of our culture (Asante, Newmark, Blake, 1979). Nonverbal behavior can communicate information in many ways and different cultures have different forms of nonverbal communication (Condon and Yousef, 1975). Consequently, the possibilities for miscommunication between cultures in an intercultural workplace setting are numerous.

Many authors have described a variety of nonverbal behaviors, the differences across cultures concerning them, 
and the problems which result when individuals from different cultures attempt to communicate. As with value differences and communication style differences, nonverbal differences may negatively affect communication. A failure to realize that there are differences and that each individual is unconsciously accustomed to interpreting only the nonverbal behavior of his/her own culture may also negatively impact on communication. In the following paragraphs, some nonverbal differences across cultures will be described. The descriptions are followed by a discussion of how they might and do impact on the communication between a manager and employee.

Two primary types of nonverbal behaviors are the use of facial expression and eye contact. Wolfgang and Cohen (1988) studied the sensitivity of various racial groups to interracial facial expressions of emotions. They maintain that individuals were more likely to interpret facial expressions accurately if they were interacting with someone of the same race or of a similar skin tone as their own. In another study, differences in the use of the eyes by African-Americans and white Western Europeans was noted. La France and Mayo (1976) found a tendency among AfricanAmerican males to avoid looking others directly in the eyes of another person while speaking, which white Western European Americans interpreted as indicating lack of 
interest or withholding. In fact, among many AfricanAmericans lowered gaze is used to signal respectful attention.

Another aspect of nonverbal behavior concerns the management of emotions. Cultures differ as to what is considered appropriate in terms of emotional expression. People in many Asian cultures are taught to mask or hide their emotions; they are seen by those who do not control them as "cold fish" or well-oiled machines. In contrast, the "controlled" cultures look at those who do not control their emotions as charming, but too emotional and likely to be unreliable (Brislin, 1982). In addition to the potential difficulties which may be caused by differences in cultural norms regarding emotional expression is the fact that some cultures try to "read" the face to determine the attitudes of another (Knapp, 1972). However, the meaning of a particular facial expression may differ from one culture to another (Samovar and Porter, 1981), leaving open the possibility of misinterpretation.

The use of silence is another aspect of nonverbal behavior which varies across cultures. Literature indicates that there are significant differences in communication norms among cultural groups. Western culture is characteristically noisier than Eastern cultures which usually include more frequent and lengthy silences (Bruneau, 
1973). Consequently, research consistently demonstrates that the reticent, quiet or apprehensive individual is perceived in European American culture less positively than the more verbal or less apprehensive individual. European Americans clearly are more comfortable with a more talkative rather than a more quiet person.

Since the communication norms within cultures act as anchors from which individuals within these cultures judge the communicative behavior of their counterparts, we are likely to find differences in the perceived attractiveness of highly verbal individuals from one culture to another. In a study of U.S. and Korean managers, the more highly verbal individual appears to be more positively perceived by U.S. managers while the less verbal individual is more positively perceived by Korean managers (Elliot, 1981). These findings suggest that a European American manager in the U.S. may find puzzling, suspicious, or incomprehensible the communication style of an Asian employee who may use silence frequently. Further, the manager may view this person less positively because of that difference.

Cultures also differ in the way they view time, leading to differences in nonverbal behavior concerning it. Western cultures tend to see time as linear, believing in a past, present and future (Stewart, 1972). Since time is linear, it is divisible, yet it is also a limited resource. Asian 
cultures, on the other hand, view time as more circular, that events tend to occur in cycles, and that time is unlimited. In the latter view, events are thus the result of multiple causes, contingencies and relationships. The differences in these two views can be observed when considering planning and punctuality. From the inductive viewpoint, time is seen as a chain of events, lends itself much more easily to the concept of planning. Mainstream U.S. managers develop plans of action, believing that the progression of events can be planned out to a logical conclusion. However, if one believes that multiple contingencies and relationships are involved, it is difficult to rely much on planning.

Punctuality is also less valued in some cultures than in others. Time itself is treated more casually. Living in the moment and enjoying relationships may be more important than obeying the arbitrary laws of the clock and producing a finite item, such as a product (Condon and Yousef, 1975). Another result of this differences in values regarding time concerns the amount of time cultures allot for different types of communicative interaction. Because of their emphasis on the conservation of time, mainstream Americans tend to be brief in their verbal communication. To be succinct and to the point is considered a virtue (Jensen, 1970). In contrast, Arabs talk a lot and repeat 
themselves, and if one only makes a statement once, Arabs may wonder if the speaker is really sincere (Nydell, 1987).

Regarding another area of nonverbal behavior, that of body movements, Mark Knapp (1972) noted that status, level of positive/negative feelings toward the other, emotional arousal, and inclusiveness can be indicated by specific body movements. His comments are generally very specific to European American culture, yet they suggest the many ways in which nonverbal behavior in the form of body movements can communicate messages to the other parties in the communication situation. As with messages conveyed by other nonverbal behaviors, intercultural communication research suggests that those messages may be misinterpreted or misunderstood because of cultural differences regarding their meaning.

Roles. A role is a "script" that an individual follows because it prescribes how that individual should behave in a particular situation. Condon and yousef (1975) noted that we tend to communicate more with roles and with representatives of the social structure than with real people. They also noted that when we communicate across cultures, we tend to be more self-conscious about our "performance". Yet what is considered appropriate behavior for each role varies across cultures (Hofstede, 1984). Thus, a manager might believe he or she is performing his or 
her role satisfactorily, while an employee from another culture may see the manager's behavior as totally inappropriate to the employee's conception of how a manager should behave.

Thus, the field of intercultural communication suggests issues and potential barriers to effective intercultural communication which may occur in the workplace. These issues include stereotyping, attribution, projected cognitive similarity, and differences in role perceptions and nonverbal communication. These barriers are generally due to cultural differences and the resulting differences in values and appropriate behaviors; further, they are a result of a lack of awareness of those differences.

Effective Intercultural Behaviors - Research Findings from Management and Communication Research

What does research in this field have to say about skills, behaviors, and techniques which are effective in dealing with these issues? Many of the skills recommended in standard management texts for effective interpersonal communication are also recommended by researchers in intercultural communication (Moran, 1979): the ability to listen effectively, to be able to give useful feedback and to be nonjudgmental are all skills recommended in intercultural communication literature. Another necessary element in communication effectiveness which is cited both 
in interpersonal and in intercultural communication is a climate of openness between manager and employee (Burke and Wilcox, 1969).

The universality of this need for openness was established by Burke and Wilcox (1969) comparing the responses of employees from eight different countries representing all major continents and across a variety of industries. The study concluded that there was strong support for the idea that all employees are favorably predisposed toward an open climate between manager and employee, and that employees favor managerial feedback that is open, accepting of the employee, and sincere. In short, many authors believe that some of the same skills which make for effective communication in one culture are also useful and even necessary when communicating with someone from another culture.

Are any additional communication skills or traits necessary for managers to possess to manage a multicultural workforce? This question has been explored by researchers both in the field of intercultural communication and in cross-cultural management. Many authors in the area of cross-cultural management (Harris and Moran, 1979; Adler, 1986) believe that prior to the development of effective interpersonal communication skills, another stage must occur. The works surveyed in intercultural communication 
for this thesis generally agree that the first step in effective intercultural communication is the development of an awareness of difference in the communicative behaviors of the two people involved (Harris and Moran, 1979). A closely related second concept is the development of an awareness of one's own behaviors and the influence of culture on them (Harris and Moran; Copeland, 1988). In fact, cultural selfawareness is seen as essential to fully understanding another culture (Rash, 1988). This awareness must be developed before any effective behaviors or skills can successfully be learned and used (Paige, 1986).

Following a development of self-awareness and understanding of differences in communicative behaviors across cultures, a manager can begin to exercise good interpersonal communication skills with his/her employees. However, as we have seen from the literature on intercultural communication, the verbal and nonverbal signals for conveying the same message (such as openness) may not be the same from one culture to another. Consequently, prior to using these skills, the manager must learn about cultural differences regarding communication. The manager of a multicultural workforce, for example, must not only convey an attitude of openness toward a minority employee, but make sure that is the message being received by the employee. Similarly, a manager must be aware of 
different nonverbal signaling systems; he or she must be sensitive to the fact each person tends to interpret another's signals in terms of one's own signalling system. Consequently, a nonverbal message of the manager's may be misinterpreted by the employee; the reverse is also true. Cultural awareness is also necessary in the use of other communication skills as well. An effective interpersonal skill frequently mentioned in communication literature is that of the use of feedback (Paige, 1986). Feedback has been defined in many ways, but it is essentially giving back to a person information about whether or not you have received his message and your reaction to $t$ his information. In the workplace, it often takes the form of information from the manager about how the employee is doing. There are many different types of feedback: descriptive, interpretive, and evaluative are three such types (Tortoriello, 1978). The skill is in giving the appropriate type of feedback in any given situation. In the intercultural context, the additional challenge for the manager is to give feedback in a way that is recognizable, nonthreatening and usable to the minority employee. One author (Jensen, 1988) has suggested that before problems can be solved or task cooperation is possible, sources of cultural conflict must be recognized and addressed. These sources can include differences 
regarding uses of language, uses of paralanguage, conceptions of time, and conceptions of space. The multicultural manager must have the skills to effectively address and deal with these potential conflict areas.

Beyond intercultural skill development, other elements are desirable. Harris and Moran (1979), in discussing the effective multicultural manager, note that such a manager must also not only tolerate but appreciate each culture's distinctiveness, a concept which is shared by Brislin (1982). This trait is sometimes referred to as valuing diversity - recognizing differences in people and seeing those differences as a valuable organizational resource (Hayles, 1978). This valuing can take place at two levels: interpersonally, by examining one's assumptions about difference and being open to difference, and organizationally, by using diversity to suggest a wider range of approaches to a problems, alternative solutions, etc. (Hayles, 1978). The difficulty is that in U.S. culture, a recognition of difference is not encouraged. Cultural norms encourage managers to ignore differences as to color, race and ethnicity and to emphasize sameness (Hayles, 1978).

The manager must therefore not only possess certain skills, but also certain traits. Additional suggested traits (Paige, 1986) include: 1) a tolerance for ambiguity; 
2) the ability to appreciate that others have a legitimate point of view; 3) multidimensionality-the ability to consider several factors when thinking about an issue; and 4) a positive self-concept or self-esteem. The trait of positive self-esteem is particularly important because those with high self esteem do not feel threatened by others and thus have a more positive attitude toward outgroups.

Many authors (Hofstede, 1984; Ruben, 1977) describe these same traits when discussing general intercultural communication competencies. A tolerance for ambiguity has been defined several ways but essentially means the ability to deal with conflicting and sometimes contradictory information by suspending judgment and withholding immediate evaluation. Paige, Hofstede, Feingold, Ramirez, and others also mention empathy, or the ability to see a situation from another person's perspective, as a desirable trait.

There are three attributes mentioned as desirable for a cross-cultural trainer (Paige, Feingold, Hannigan, 1990) which are also mentioned by Hofstede as desirable for a manager. They are: flexibility, patience, and commitment to effective communication. The flexible manager was described by Adler (1986) as responding, in terms of leadership style used, to the type of audience with whom he or she was dealing, thus calling to mind the theory of situational management. 
In summary, research drawn from literature in management, organizational behavior and intercultural communication can tell us a great deal about potential communication issues and the factors related to those issues in the intercultural workplace. This research also suggests means for addressing those issues. It suggests that a multicultural manager must build on the interpersonal skills needed by any manager, i.e., effective listening or giving feedback, but also must possess an awareness of the influence of culture on his/her own as well as others' behaviors and thinking. In addition, he or she should possess a number of traits, 1) flexibility, 2) a tolerance for ambiguity, 3) a sense of empathy and 4) a positive self concept. He or she should also know how to value diversity. The research suggests that with these traits and skills, the multicultural manager has a much better chance of communicating effectively with those from other cultures who might be in the workforce the manager supervises.

Although the research clearly suggests a good deal of potentially useful information, in the view of this researcher, two gaps exist in that research. One gap is that this information must be drawn from a number of sources and three areas of study. As of this writing, little research has come to the attention of this researcher which effectively draws from all three of these areas to present a 
unified approach with strong theoretical foundations concerning communication issues in the management of a multicultural workforce. The second gap which exists, in the view of this researcher, is that the validity of the information suggested in the literature concerning communication issues and behaviors in the management of a multicultural workforce has not been widely investigated in the U.S. multicultural workplace. In other words, there is little research to suggest that the issues and behaviors described in the literature about cultural difference in general are those experienced in the U.S.multicultural workplace. To address this situation, the following research questions were explored for this thesis:

1. What do managers report as communication issues in the management of a multicultural workforce?

2. What do managers report as effective behaviors in addressing these issues?

3. How do the reports of the managers compare to communication issues and effective behaviors discussed in communication, organizational behavior, and management research? 


\section{CHAPTER II}

\section{METHODS}

This research took an exploratory approach, using the interview as a method of data collection. Interviews were conducted with managers of diverse workforces at three different companies in the Portland area. The purpose of the interviews was to address the previously described research questions and to compare the results with themes suggested by the Iiterature review.

\section{PARTICIPANTS}

The managers interviewed were selected from the oregon Directory of Manufacturers. A list was compiled of manufacturing companies with over 100 employees, but preferably 500 or more employees. Companies of such size were more likely to have at least some minority representation in their ranks than would smaller companies. Five companies were selected from the list. The human resources representative in all five companies were contacted by this researcher. Prior to the contacts, permission was granted by the Human Subjects Research Committee at Portland state to conduct the interviews. 
The method of contact is described in subsequent paragraphs. of the five companies contacted, three were willing to participate in the study. The companies contacted were each involved in a different line of manufacturing. This approach was used to explore the experience of companies involved in different areas of manufacturing, yet still operating under the umbrella of manufacturing.

The human resources representative was contacted in each of the companies to confirm that representatives of minority groups were present in the workforce and to determine the groups represented and the percentage of representation for each group. These calls were also made to gather more information about the company, its policies regarding minorities, and to obtain suggestions for the names of managers who might be interested in being interviewed. This researcher considered the most appropriate manager to be the one who worked closely (such as through direct supervision) with the minority employees. The goal was to interview a mid-level manager who was responsible for the management of a minimum of one hundred employees, at least ten percent of whom were minority. However, after considerable effort, it was only possible to locate one manager of a larger workforce; the other managers who consented to be interviewed had workforces which were considerably smaller - from twenty to fifty people in the 
group. In each of these cases, though, the number of minority employees was at least nine percent or more of the total group managed; in one case, it was thirty percent. Following the initial phone research, the manager was contacted by phone for permission to conduct the interview, then contacted again by letter to confirm the appointment and to supply the release form required by the Portland State University Human Subjects Committee to conduct such research.

\section{PROCEDURES}

Interviewing was the method chosen for this research. This method contains strengths and weaknesses. It was chosen over other methods such as mailed questionnaires or observation because of the degree of flexibility and detail which was not possible through the other methods. This researcher sought to obtain somewhat detailed information about particular types of communication situations experienced by a few managers.

Interviewing was selected as a method because of the need for follow-up and probing questions. Also, given the scope of this thesis, no assumption was made that this research represented a statistically valid sampling technique; such an undertaking involved extensive survey costs and required the consideration of a host of new 
variables. Portland area managers were surveyed because, during the initial research for the thesis, phone conversations by this researcher with human resource managers at several large Portland area manufacturing companies revealed that minorities represented five to ten percent of their total workforce. No actual statistics could be found to indicate the specific number of minorities employed in manufacturing.

McCracken (1984) suggests that, prior to conducting the interviews, the interviewer examine his or her own assumptions and feelings about what he or she will find. Doing so assists the interviewer in spotting his/her own biases and assumptions in question formulation and in the analysis of the interviews. This researcher assumed:

- that the interviewees had experienced different communication situations with minority employees than with white employees (assuming the manager was white);

- that the managers would report some difficulties in intercultural communication; if no problems were reported,

- the manager either had the skills to deal with the situation or didn't realize that problems were occurring. 
The interview approach used was scheduled and semistructured; the same questions with virtually the same wording were asked of each respondent. They were also asked in the same order. When this researcher wished to probe for more information or pursue a particular point, this was done. Thus, the wording of actual questions differed slightly in form from one interview to another. A standardized list of questions was used, but probing questions were also used to follow up on points the interviewer pursued or clarified. Open-ended questions were generally used; they encouraged explanations and elaboration rather than closed-ended "yes" or "no" responses. The questions asked to elicit the desired information are described in Appendix A.

The interview itself involved a four step process: -establishing rapport - pleasantries and expression of appreciation

-providing orientation-reviewing the purpose, nature and length of the interview, how it will be used, etc. (Mccracken, 1988)

-asking the interview questions

-closing - declaring the completion of the task and expressing appreciation

The questions were organized to initially elicit background information concerning the nature of the 
responsibilities of the manager and additional information concerning the type of workforce he or she managed. Later questions were designed to encourage the manager's perceptions of several events and the feelings generated by them. The format helped the researcher understand how the managers thought about communication in two types of situations (Saville-Troike, 1982). Some of the questions were designed to inform the interviewer about the corporate culture; others related more to the particular style employed by the manager.

The first part of this interview format was designed to provide background information on the individual manager and the situation. The second part was designed to establish a context and to begin to determine the nature of the corporate culture and how it might influence the manager's style of leadership. The section of the interview labeled "orientation-content" continues to explore the corporate culture. The third part of the interview probed specific intercultural communication situations.

The interview opened according to the four step process mentioned earlier and also included a few remarks by this researcher to indicate her knowledge of the demographics of the company's workforce and its affirmative action policies. For example, this researcher mentioned that she had spoken to the human resource representative and understood that 
approximately ten percent of the work group supervised by this manager were non-mainstream American. This researcher received manager consent to use a tape recorder to tape the interviews.

Each interview lasted approximately one hour. In each instance, the interviewee expressed interest in obtaining a copy of the research results, as contained in this thesis. A list of the actual interview questions is found in Appendix A.

\section{DATA ANALYSIS}

This study explores, through the interview method, manager perceptions of communication issues in the management of a multicultural workplace, and the behaviors which the managers reported they used to address these issues. Thus, the reported subjective experiences of the interviewed managers is the concern of this study. The results of the interviews were analyzed to determine what intercultural communication issues were reported by managers in that particular workplace and what behaviors they reported as effective in addressing those issues. The data were organized according to 1) the type of questions asked, and 2) the type of responses received. Themes emerging from the analysis of the data are discussed in the results chapter according to the type of communication issues 
described by the managers for example, whether the issues concerned verbal or nonverbal behavior. More specific categories of themes are described using the categories suggested by the literature review, for example, the use of eye contact as a nonverbal behavior, or the use of paraphrasing as a communication skill. Examples of that clustering are found in the appendix.

There were essentially two basic situations examined in the interviews and two types of questions asked about each situation. The two situations were 1) giving orientations and 2) giving instructions to employees. For both types of situations, the questions concerned the type of issues which existed and the consequent behaviors reported by the managers as effective methods of addressing the issues.

\section{MANAGER DEMOGRAPHICS}

In the following pages, the three separate organizational and manager situations are described.

Manager Number one is the supervisor of a division of 43 people which puts together a complete product from start to finish. All divisions in the company operate essentially as small companies; each is responsible for its own budgeting, staffing, forecasting, and overhead. This approach to manufacture of the products was adopted a few years ago; formerly each division was responsible for one 
type of process in the production of several types of equipment.

Manager Number One has been with the company since 1979. Previously he worked in manufacturing management, in personnel hiring and in production line supervision. His experience also includes managing a plant for the company in Latin America.

The group he manages includes people with a variety of skills, from very low to highly skilled. Of the group, eight are non-mainstream Americans; the group includes Southeast Asians, blacks, Latin Americans, and one Native American. Entry level skills required in his department include math, reading and writing skills, with a high school diploma preferred. Ninety percent of the workforce in this division is female. Part of the company culture is the approach the company has taken to production. There are three basic strands (his words) in the company operating philosophy: total quality commitment, employee involvement, and just-in-time manufacturing. All levels of employees are trained to understand this approach. Employee involvement means training employees to do a variety of tasks to help each other out when necessary, to understand the whole process, and to become involved in the improvement of production processes. 
other parts of the culture include a team orientation and a philosophy that everyone's job is important and their contributions are to be respected. The employees can share in the profits of the company through a special program. Recognition awards are given for outstanding contributions, and employees who have worked ten or fifteen years are taken to lunch and dinner. Company customs include a summer picnic, a Christmas luncheon, a blood drive, many sports teams, and a group of regularly operating fundraisers.

Manager Number Two is a general supervisor; nine managers report to him and he is directly responsible for the work of 320 employees. This manager does not do day to day supervision at this stage of his career (as he did formerly), but he sees and talks frequently with employees on the line. He also handles personnel problems brought to him by his managers, occasionally meeting with employees. This manager has worked with his company virtually all of his adult life, over twenty years. During that time, he was a manager for 14 years and a general supervisor for six. His duties now generally center around teaching and coaching his peers and the managers he supervises concerning the implementation of a world class quality philosophy in the company. For example, he discusses "world class quality", what does this mean in terms of thinking, and other companies' experiences regarding the use of this philosophy. 
Some of this philosophy is expected to "cascade" down to the individual employee.

Approximately nine per cent of the employees he supervises are non-mainstream white Americans, with these numbers varying slightly year by year. This group includes fifteen Asians, ten Hispanics and two blacks.

Manager Number Three is a manufacturing manager who is responsible for a product line involving approximately sixteen employees, and operations responsibilities for five to six more. She also sets priorities for people in related departments. She began with the company over twenty years and has been a manager there for almost fifteen. The people she directly supervises are generally operator technicians, but she also supervises the work of engineers, a supervisor and other support people. Thirty percent of those individuals are non-mainstream white Americans; virtually all of this thirty percent are Asian. This manager sees as her primary responsibilities the setting of priorities for the groups and the assuring of smooth operations by a constant watch of the inputs (including resources) and the final results.

The company philosophy is to produce an excellent product. She sees the group she supervises as more team than competition oriented because they are entirely dependent on each other to produce the products. She 
believes that the company orientation is currently more competitive, but seems to be moving back toward a team orientation. The company has undergone radical change in recent years; as a result the philosophy may be changing. Several company activities are no longer practiced, such as a company picnic. However, there are blood drives and a semi-annual business/social meeting. Generally, activities are arranged by the individual division. Awards are given for service recognition. 
CHAPTER III

RESULTS

The purpose of this interview research is to discern whether certain themes emerge from the communication issues reported by managers of multicultural workforces. Certain themes could be identified as a result of an analysis of the clustered data concerning both the communication issues and the responding behaviors identified by the managers for the orientation situation and the instruction situation. Themes identified regarding employee orientation were analyzed separately from themes concerning the instructing of employees. Examples of data clustering are found in Appendix B.

$$
\text { EMPLOYEE ORIENTATION -- ISSUES }
$$

Two major themes emerged concerning communication issues: nonverbal differences and language differences. Data analysis indicated that two of the three managers identified nonverbal behavioral differences as obstacles to communication. Two of the three managers reported what they considered confusing nonverbal communication by some minority employees. One of the managers reported that "he had difficulty in interpreting the behavior of some Asians 
he supervised." Some minority employees would nod their heads in response to verbal messages and the managers were unsure how to interpret that action. They eventually interpreted it as indicating comprehension, yet lack of comprehension was either ascertained by the manager through questioning or later became clear when employees failed to carry out the verbal messages they had received. One manager also reported that these same employees also asked few questions. Interestingly, the managers reported differences in duration of eye contact and silence between themselves and some employees, but did not report these differences as presenting communication issues.

The nonverbal behavior of the managers and supervisors may have caused intercultural communication difficulties, at least in the view of one manager. One manager reported that communication styles used by supervisors in his organization were often "direct" and "firm" and he perceived that style to be frightening to the Vietnamese employees. Another nonverbal behavior, that of paralanguage was also mentioned by this manager; he believed that the supervisors' voices seemed loud and abrupt to some minority employees.

The other theme which emerged as a communication issue concerned language difficulties. Two of the three managers reported difficulty on their part in understanding the words of some minority employees. One manager reported that he 
had observed supervisors "breezing through" an orientation because they were uncomfortable with language differences or a perceived lack of understanding by the employee. This manager reported that he perceived a tension in this type of situation.

Conversely, the managers also perceived that some minority employees had difficulty in comprehending their words and attendant meanings. This conclusion was based on employee behavior following manager conversations with employees, and manager interpretation of employee nonverbal communication. One of the managers reported that this issue had occasionally become critical but had not surfaced until months after the orientation. Some of the orientation involved explanation of safety procedures around machinery. In a few instances, a procedure had not be followed due to alack of understanding or misunderstanding of orientation information. Safety hazards involving large machine use had resulted and employees were either in danger of serious injury or in danger of causing injury to others. The manager at the company reported that these incidents were initially thought to be due to failure by the employee to do the work properly, but eventually he and other managers came to the conclusion that the incidents were due to language barriers during the orientation. They came to this 
conclusion because the employees involved were otherwise quite competent in their jobs.

\section{EMPLOYEE ORIENTATION -- RESPONDING BEHAVIORS}

Examination of the data concerning reported manager behaviors which addressed communication issues reveals two major themes: reported modification of verbal and of nonverbal behaviors. Two of the managers reported that they modified their verbal communication by using paraphrasing (or similar) techniques and by asking questions to check employee comprehension. Repetition of the information and use of simpler words was also reported by these managers. The same two managers reported that they made two types of nonverbal modifications in their communication styles: changing their paralanguage and changing their facial expressions. The two managers reported that they slowed their speech when speaking with minority employees. One of these managers said that "he does recognize that he talks slower to foreign-born employees". The other manager reported that an examination of facial expressions of first line managers during orientation was made. He and others observed that the first line managers rarely smiled during orientations. His conclusion was that the minority employees probably had difficulty in interpreting the facial expressions of managers giving orientations (although he 
didn't describe these expressions or say why he thought some minority employees might experience difficulties), and were confused by these expressions as to their meaning. As mentioned earlier, he also believed that some employees might be a little frightened by this approach. He believed that this confusion was due to cultural differences in displaying emotions in the face.

This manager reported a modification of approach after examination of the orientation process with minority employees. He and other managers decided to "stop and look at the process." He reported that he and his managers realized that their approach tended to be matter of fact and direct, and that they probably smiled less frequently than some of the minority employees might expect. He commented that the "paradigms" might be different amongst cultures; they assigned different meanings to behaviors and some employees might be a little frightened by what they saw in supervisor behavior. Consequently, he and his supervisors attempted to modify their behavior to be less direct in their manner, less abrupt in their speech, and to smile occasionally to convey a warmer, more relaxed tone.

\section{GIVING INSTRUCTIONS TO EMPLOYEES -- ISSUES}

Examination of the data for these questions indicate that the types of communication issues which arose in giving 
instructions to minority employees were very similar to those reported concerning orientation situations. Therefore, similar themes emerged from analysis of the data. Language difficulties were reported by all of the three managers as communication issues. Again, these difficulties were experienced by both parties: the manager had difficulty understanding the speech of the employee, and the manager perceived the employee as having difficulty understanding him.

Two of the three managers reported nonverbal behavior which created communication difficulties. Two of the managers again reported what they saw as inappropriate behaviors: some employees nodded to indicate understanding and the managers perceived that there was none. The managers also reported difficulty in "reading" the facial expressions of some minority employees.

one communication issue which emerged as a theme from general managerial comments concerned attribution. Comments were made by all three managers concerning work habits and/or communication styles of different cultural or racial groups. These comments related to employee general attitudes as perceived by the managers and were not reported as specific communication issues. However, since intercultural communication research indicates that attribution influences our behavior toward others, it is 
appropriate to report the anecdotal comments.

Concerning southeast Asians, one manager reported that they "showed a lot of respect for authority and initially, for their peers." Another manager commented that "Asians work harder here"; "they want to work more" and would work weekends if allowed.

Finally one manager commented "we've come a long way in terms of how we deal with minorities, but we still have a ways to go". He made this comment at the end of the interview to summarize the situation at his organization.

\section{GIVING INSTRUCTIONS -- RESPONDING BEHAVIORS}

Examination of the data regarding responding behaviors shows a wider range of responding behaviors for the "giving instructions" type of situation than for the orientation type of situation. The data indicates two themes: a reported modification of behavior which occurred almost solely in verbal behavior, and the use of various communication skills to clarify and improve comprehension.

Verbal modification included the use of simpler words and shorter sentences, and the elimination of slang. The only reported nonverbal behavior modification involved a slowing of the managers' rate of speech and attention to eye contact. One manager reported that he made a greater effort to maintain eye contact as a means of increasing 
communication. Research shows that white mainstream Americans put a greater emphasis on the use of eye contact to communicate than do many other cultures.

Two of the managers reported that they used several communication techniques to improve their communication with some employees. These techniques included:

- rephrasing of information

- repetition of information by manager or by employee

- "better" listening

- questioning employees to check employee comprehension or to clarify message received

- the use of "test" statements

One manager's examples of questioning were to ask "Did you understand?" and "could you repeat it back to me?" Another manager said that he would say "How do you say it in Spanish?" or would ask "Is there something you didn't understand?"

For the "test" technique, a meaningless or incorrect instruction was given; if the employee nodded agreement, the manager knew that s/he didn't understand the communication.

Two of the three managers also requested behavior modification by some minority employees in the process of communication. Manager Number Three asked for more input and information from some employees, thus requesting behavior modification on their part to suit her managerial 
style. She had observed that some southeast Asian employees were silent or did not talk as much as their EuropeanAmerican counterparts when in a small group setting. She consequently spoke to them separately, told them that their expertise was valuable, and asked them to contribute more in the group. She told them that she realized that this action might make them uncomfortable and mentioned to this researcher that their discomfort might be due to a cultural tendency of not speaking up in a group. Manager Number Two asked minority employees to tell him if there was something they didn't understand. Their compliance might involved some behavior modification on their part, if they were not culturally comfortable in acknowledging to a superior that there was something they didn't understand.

The two skills or techniques that all three managers reported that they used were better listening (which they defined as listening more carefully) and asking questions. All three managers specifically cited those techniques. One manager reported that the organization decided that the supervisors and managers needed to modify their approach when giving instructions to southeast Asians. They were instructed to be more relaxed and to get more feedback, also to convey the attitude that "I'm here to help". They were also asked to get more feedback from Asian employees who tended to be more silent that their non-Asian counterparts. 
Finally, one manager reported the use of a native speaker as an interpreter and liaison to overcome language difficulty problems. The interpreters were representatives of the minority culture who had worked for some time in the company. However, this manager perceived that some employees resented the use of a liaison/interpreter because the employees "wanted very much to be accepted." All of the actions reported by these managers were considered by them to be helpful in improving communication.

One communication issue which emerged as a theme related to attribution came from general managerial comments. Coments were made by all three managers concerning work habits of different cultural or racial groups. These comments related to general attitudes perceived by the managers and were not reported as specific communication issues. However, since intercultural communication research indicates that attribution influences our behavior toward others, it is appropriate to report the anecdotal comments.

Concerning Southeast Asians, one manager reported that they "showed a lot of respect for authority and, initially, for their peers." Another manager commented that "Asians work harder here"; "they want to work more" and would would weekends if allowed. A third manager found that "Asians tend to be workaholics" and speculated that it was because 
they needed the money as one possible cause of their behavior. The same manager mentioned "less initiative" than she would like to see was more of a problem "with whites." Another manager perceived some South American employees as having some resentment for the European Americans, and for authority. The same manager reported that he had had a couple of African-American employees whose work habits he felt needed improvement. He had held conferences with these employees, but felt that communication "wasn't there." He speculated that he and his fellow managers may act differently with African-American employees for several reasons; the managers were very aware of civil rights laws, they may assume that the African-American employees should already know more about the mainstream work culture than the Southeast Asians, and lastly, they might be unconsciously more vague and abrupt with the African-American employees to "help them trip up" or make mistakes. This manager reported that he had discussed this situation with other managers to "ask them to think about what's happening, what's behind this?". He commented that being aware of this behavior was important. The last manager mentioned that he perceived "a real difference in the level of effort between the Asians and the Hispanics. The nature of all of these comments will be discussed in the following section. 
CHAPTER IV

\section{DISCUSSION}

The primary goal of the interview research was to collect data in order to compare manager responses with themes in the literature concerning intercultural communication issues in the workplace and effective behaviors for addressing those issues. Appendix $\mathrm{C}$ is a summary list of the communication issues and effective behaviors suggested by the literature. This section of the thesis will compare that list, by topic, to the interview findings. Prior to that comparison, the following overview is offered.

A comparison of issues suggested in the literature with those gathered from the data reveals that a much larger number of issues was suggested by the literature than by the managers during the interviews. The managers reported communication issues according to four general categories:

- language differences

- nonverbal communication differences

- communication apprehension

- inadequate information given to employee 
The issues suggested by the literature included all but the last category. Yet a whole host of additional issues was also suggested by the literature, such as differences in values, thought patterns, and decision making styles.

A comparison of suggested effective responding behaviors shows a high degree of similarity between behaviors suggested by the literature and those behaiors reported by the managers as effective. In general, the similarity was found in the type of skills suggested by the literature and those reported by the managers. The dissimilarity between the literature results and the interview results was that the literature also suggested traits and attitudes, as well as skills to improve intercultural communication. The managers were asked about behaviors they employed, and primarily reported skills, or behaviors learned through education or experience (Brislin, 1981). Their comments, however, did occasionally indicate that they had considered a few of the attitudes suggested by the literature. A more specific analysis of these attitudes follows the discussion concerning communication issues.

cross-cultural management theory describes the impact of culture on management, particularly noting that management styles are culture-bound and thus influence the communication process. The interviews with the managers seemed to validate this notion. All three managers 
interviewed described their management style as participatory, a style which at least in name is quite popular in the U.S. workplace today. One manager described his general managerial approach to be casual and low key; when communicating with employees he often mixes social conversation with questions about the task at hand. Another manager said he tended to "let employees solve problems by themselves" and the third manager reported that she told Southeast Asian employees that their input was needed in work groups. None of the managers indicated that they had modified their managerial style with minority employees, although three managers indicated that they had modified their communication style, in varying degrees, with minority employees. Expectations concerning managerial communication style are influenced by culture and several cultures were represented in each of these workplaces. It would be interesting to learn if minority employee expectations concerning managerial style differed from the expectations of the managers. As suggested by the work of Hofstede and Kras, these expectations might be quite different from the European American managers'.

Cross-cultural management asserts that culture influences perceptions concerning managerial roles and expected behaviors and that differences may exist between manager and minority employee concerning the manager's role 
and expected behavior of the manager. This researcher gathered data concerning the manager's perceptions of their role, but did not gather data from the employees concerning their perceptions of the manager's role. This topic was addressed extensively by Hofstede (1982) on an international scale, but little data was discovered by this researcher concerning minority perceptions in the U.S. workplace. Such research could yield some valuable clues regarding sources of intercultural communication differences.

One theme described in both the literature and in the comments by one manager was that of communication apprehension. As described in the literature review, communication apprehension occurs when individuals are faced with behaviors that seem inappropriate or incomplete and for which they are unsure of the proper response; a tension or apprehension then takes place. This phenomenon seemed to occur in the workplace of Manager Number Two. He reported that some of the managers he supervised reported feeling uncomfortable in some orientation sessions with minority employees, and would "breeze through" the orientation in order to end it more quickly.

Another theme mentioned in the literature which is considered to affect intercultural communication concerns problem-solving and the related area of decision-making. One of the managers described this area as presenting 
difficulties in intercultural communication when she reported that some of the Asian employees did not speak up in some small group meetings which focused on process problems. She felt it necessary to encourage them to participate and offer feedback in order for the process to be successful. One manager reported that his approach to problem-solving was to give employees some specifics regarding boundaries, but to let employees do some problemsolving themselves and to encourage them to do so in groups. He did not report if he had encountered any difficulty in using this approach with minority employees. One can speculate that either this style was acceptable to all minority employees or that, since the manager interviewed no longer supervised line employees, he employed the techniques he described more recently with first line managers who were not members of minorities.

The literature on intercultural communication also stresses the importance of differences in meaning as a potential source of communication difficulty. This topic did not surface directly in the comments made by the managers. However, meaning differences could be inferred from comments made by one manager. This manager reported that he occasionally used a native speaker who was also an employee as an interpreter. One can speculate that this action was an attempt to assure greater understanding of 
meanings between manager and employee, not only in terms of language translation, but also with attention to the specific context of the company's operations.

In describing the influence of values on behavior, many authors see the importance of maintaining social harmony evidenced in the difficulty members of some cultures have in disagreeing with others or saying no. This factor could have influenced the behavior of some minority employees in several types of interactions with managers, for example, nonverbally indicating comprehension (nodding) when given information by the managers. Two of the managers reported that they believed the nodding indicating comprehension was, in fact, an attempt to please the boss and not appear stupid or incapable in front of their fellow workers. Social harmony could have also been the motivation for the lack of reported instances by the managers of minority employees disagreeing with the manager.

The nonverbal behavior described by two of the managers concerned head nodding by some of the minority employees. When given instructions or orientation information, some of these employees at two sites would nod their heads, which the managers perceived as an indication of comprehension. Yet the managers reported that they believed these employees had not in fact understood the speaker. Were the employees sending out their own signals which the managers 
misinterpreted because they used the managers' signalling systems? or were the employees sending out incorrect (for the managers) signals? Essentially, these questions are at the heart of the communication issue presented.

Another difference described both in the literature and by the managers concerned differences in eye contact. All of the managers comments that southeast Asians tended to have less eye contact than the managers encountered with other employees, yet, interestingly, none reported it as a communication issue. Perhaps all three managers were aware that less frequent eye contact was a cultural tendency among many Asian cultures.

Differences in nonverbal behavior on a more general level seem to have been a communication issue for Manager Number One. He reported that he "had difficulty in interpreting the behavior of some Asians he supervised." He remarked that they sometimes bow to him but "that's their culture."

Factors which the literature described as potential communication issues, such as differences in values, conversational rules, and thought patterns were not described by the managers as communication issues. Their absence may be due in part to the nature of the questions asked. 
A number of the various works surveyed for this thesis suggest the use of certain skills and attitudes by managers to improve communication. Several of these skills, such as paraphrasing, improved listening, and the use of constructive feedback were also cited by the managers as useful in improving their communication with minority employees. These particular skills are described in the literature on interpersonal communication. The managers also cited other techniques generally not referred to in the literature, such as using different words to say the same thing, and techniques to slow down their rate of speech or to simplify their language. Two of the managers also described using "test" statements to check comprehension; the same two managers asked employees to occasionally repeat back what they had said when employee comprehension was questionable. One manager reported the use of an interpreter when language difficulty situations arose. All three managers said that they questioned employees when they were unsure if the employees understood them. One manager commented that he tried to increase eye contact with Southeast Asians when addressing them.

In addressing intercultural communication issues, the literature generally suggests that the manager analyzes his/her own behavior to understand how it is culturally influenced. Two of the three managers did indicate that 
they had done some examination of their own communication styles in order to identify the source of some communication difficulties with minority employees. One manager's comments regarding different images each person had of another indicated that he had analyzed behavior in terms of perceptual differences. However, in the three cases examined, the data did not suggest that an examination of behavior was carried out by the managers at the values level. For example, none of the managers made any comments regarding perceived differences among cultural groups in the organization concerning cooperation and group achievement versus competition and indvidual recognition. Similarly, none of the managers mentioned an awareness of cultural differences regarding thought patterns, decision-making, or role expectionas regarding managers.

This awareness of fundamental differences across cultures, along with an awareness of self as a cultural being, is considered essential in intercultural communication literature for effective intercultural communication. One can speculate 1) that the interview questions were not phrased to suggest these analyses, 2) or that communication between manager and minority employee was sufficient to carry out organizational tasks so that such analysis was not (as yet) necessary, 3) or that the manager 
was not aware of these fundamental differences and how they might affect communication.

None of the managers specifically described any attitudes that they employed when attempting to communicate with minority employees. However, many of the behaviors they described as taking, and their unsolicited comments about the employees indicated various attitudes they employed, such as empathy. One manager said he believed that some of the minority employees were nervous and wanted to make a good impression and to do well for the group. As a result, they were eager to indicate that they understood the instructions and nodded their heads in acknowledgement. In the comments made by this manager and another, there appeared to be an attempt to view the communication situations of at least some of the non-mainstream American employees from their own perspective. An attitude of flexibility was illustrated by the fact that the managers (the degree varied by the individual) were willing to modify their own communication style in order to improve communication.

Two of the managers indicated that they attempted to present an attitude of openness toward minority employees, for example, one manager stressed that supervisory were encourage to interact, spend more time and convey an "I'm here to help" attitude to southeast Asian employees. 
Another manager described his approach as casual and low key and tried to be available at all times to employees.

It is interesting to note comments made by one manager concerning his treatment and the treatment of his supervisors of different racial groups. This manager had observed what he perceived as a significant difference in the communication style used by himself and other managers with African-Americans versus Asians. The communication style used with African-Americans he believed to be more abrupt, more direct, and the words more carefully chosen. He believed this difference to be due to a strong awareness of the civil rights laws affecting employer/employee relations and an effort not to get into legal difficulties. He attributed this situation to different "paradigms" we all have regarding different ethnic groups; part of those paradigms had to do with the history of relations between the white and the minority culture. His comments seem especially meaningful in light of condon and Yousef's (1975) statements about communicating with roles and images, rather than individuals. Not specifically mentioned were the terms "stereotype" and "prejudice".

All three managers made comments during the interviews concerning the "hard work" orientation of a number of the Southeast Asians in their work group. It was clear that this orientation was viewed favorably by the managers. An 
expected result would be a more favorable attitude toward the Southeast Asians. Additionally, two of the managers noted that other minority members of their group possessed different work attitudes, and that these attitudes were not as favorably considered by the managers.

What does the interview data tell us about these managers' attitudes toward the changes they had made and toward cultural differences? These questions were not explicitly asked, however, one can speculate about them from the results of the interviews. All of the managers conveyed positive feelings about most of the minority employees they supervised, particularly those who probably held similar work values. All of the managers seemed willing to make some adjustments in their communication styles to achieve better communication with most minority employees. None of the managers conveyed negative feelings about the changes that they had to make in their communication.

However, this researcher did not detect that changes had gone much beyond surface interaction with employees. For example, all of the managers employed a participatory management style (a style particular to the U.S.) with all employees and virtually all of the communication difficulties they reported concerned behaviors rather than attitudes. The managers did not demonstrate an awareness of cultural differences concerning individualism versus group 
identification or the value of social harmony versus honesty. The skills they employed for better communication were generally not adjusted for cultural differences, i.e., conveying a sense of openness. When discussing work attitude differences among employees, these attitudes were described positively or negatively, without a comparison of their similarity to or difference from European American values. This researcher speculates that the managers interviewed were dealing with cultural differences primarily on the level of communicative interaction, rather than on the level of fundamental value differences. The fundamental level may not have been addressed for several reasons: a lack of time to think about it, a lack of awareness of fundamental cultural differences, the absence of a recognized need to do so, or the presence of a degree of ethnocentrism. The last element might be evidenced in an expectation that, while the managers would be willing to make some modifications in their behaviors, they expected minority employee behavior to generally conform to the corporate cultures in which they worked, which were all strongly influenced by European American values.

\section{LIMITATIONS OF THE RESEARCH}

Limitations of this research concern the type of questions asked and the type of participants interviewed. 
The nature of the questions asked did not encourage the managers to discuss attitudes they found effective when communicating interculturally or their beliefs and attitudes regarding intercultural communication; rather they were asked to discuss demonstrable behaviors and skills in two contexts. Only two contexts were used because it was anticipated that the interviews would be too lengthy with more contexts, and the managers would probably be unwilling to spend additional time. However, the contexts chosen were those very commonly experienced by managers working with minority employees. Additionally, perhaps if questions regarding values or attitudes had been asked of the managers, the results would have more closely matched themes in the literature. With regard to the interviewees, interesting additional information might have been obtained if employees were interviewed concerning the same questions asked of the managers. Only three managers were interviewed, including two male and one female manager. Additional interesting data might have been obtained if the responses of three male managers were compared with the responses of three female managers.

\section{CONCLUSIONS}

In reviewing the results of the interview research and the literature review, this researcher's conclusion is that 
the results of the interviews present some contrasts as well as similarities to issues and behaviors described in the literature.

How to manage a multicultural workforce is perhaps one of the most discussed topics in the field of management today. In response to this situation, there is a growing body of literature (and number of experts) on the topic. Yet, as this thesis attempts to demonstrate, research must establish a stronger link between what the literature says are intercultural communication issues in the workplace and what the managers actually report. That connection will establish a firmer basis for practical intercultural communication training for managers. Because very little data now exists, the topic of minority employee perceptions of manager/employee communication difficulties could also be explored.

Another area also needs further research. According to a study conducted in 1991 (Van Eron) of human resource professionals, there is a definite need for empirical research that supports the case that a diverse workforce is related to organizational productivity. Data indicating such an idea would go a long way in convincing managers of the importance of improving their communication with their multicultural workforces. 


\section{REFERENCES}

Adler, Nancy. (1986). International dimensions of organizational behavior. Boston: Kent International Business Series, Wadsworth Publishing

Althen, Gary. (1988). American ways. Yarmouth, Maine: Intercultural Press.

Althen, G. (1981) - Learning across cultures: intercultural communication and international exchange. Washington, D.C.: National Association for Foreign Student Affairs.

Argyle, Michael. (1982). Intercultural communication. In Stephen Bochner (Ed.), cultures in contact, (pp.6180). Oxford: Pergamon Press.

Asante, Molefi and Barnes, Alena. (1979). Demystification of the intercultural encounter. In M. Asante, E. Newmark, C. Black (Eds.), Handbook of intercultural communication, (pp. 95-104). Beverly Hills: Sage Publications.

Asante, Molefi and Alice Davis. (1989). Encounters in the interracial workplace. In $M$. Asante \& W. Gudykunst (Eds.), Handbook of international and intercultural communication, (pp. 374-391). Newbury Park: Sage Publications.

BNA Communications, Inc. (1990). The challenge of diversity. Rockville, MD: BNA Communications, Inc.

Bailey, Kenneth. (1988). Methods of social research. New York: The Free Press.

Barna, LaRay. (1982). Stumbling blocks in intercultural communication. In L. Samovar \& R. Porter (Eds.), Intercultural communication: a reader (4th Ed.), (pp. 322-330). Belmont, CA: Wadsworth Publishing. 
Barnlund, Dean. (1981). Communication in a global

village. In Larry Samovar and R. Porter (Eds.),

Intercultural communication: a reader (4th

Ed.), (pp.4-14). Belmont, CA: Wadsworth

Publishing.

Barnlund, Dean. (1962). Toward a meaning-centered philosophy of communication. In J. Stewart (Ed.), Bridges not walls (4th Ed.), (pp. 36-41). Reading, MA: Addison-Wesley Publishing Co.

Barnlund, Dean and Yoshika, M. (1990). Apologies: Japanese and American styles. International Journal of Intercultural Research, 14(2), 193-206.

Bennett, Milton. (1988). Foundations of knowledge in international educational exchange. In Joy Reid (Ed.), Building the professional dimension of educational exchange. Washington, D.C.: National Association of Foreign Student Advisors.

Bochner, S. (1982). The social psychology of crosscultural relations. In Stephen Bochner (Ed.), Cultures in contact, (pp. 5-44). New York: Pergamon Press.

Brislin, R. (1990). Applied cross-cultural psychology. Newbury Park, CA: Sage Publications

Brislin, Richard. (1982). Cross-cultural encounters. New York: Pergamon Press.

Brislin, Richard., Lonner, Walter and Thorndike, Robert M. (1973). Cross-cultural research methods. New York: Wiley \& Sons.

Brislin, Richard, Cushner, K., Cherrie, C., Yong, M. (1986). Intercultural interactions. Beverly Hills: Sage Publications.

Bruneau, Thomas. (1973). Communicative silences: forms and functions. Journal of Communication, $\underline{2}$, 17-46.

Burke, R. and Wilcox, D. (1969). Effects of different patterns and degress of openness in superiorsubordinate communication on subordinate job satisfaction. Academy of Management Journal, 12(3), 319-326. 
Carbaugh, Donald. (1985). Cultural communication and organization. International and Intercultural Communication Annual (IICA), 9, 30-47.

Casse, Pierre. (1979). Training for the cross-cultural mind. Washington D.C.: Society for International Education, Training, and Research (SIETAR).

Casse, Pierre. (1980). Training for the multicultural manager. Washington, D.C.: SIETAR

Child, John (Ed.). (1973). Man and organization: the search for explanation and social relevance. New York: John Wiley and Sons.

Condon, Jack and Yousef, Fathi. (1975). Introduction to intercultural communication. Indianapolis: BobbsMerrill Co.

Coates, J., Jarratt, J., \& Mahaffie, J. (1990). Future work. San Francisco: Jossey-Bass Publishers.

Copeland, Lennie. (1988, May). Learning to manage a multicultural workforce. Training, (25)5, pp. 49-58.

Copeland, L. and Griggs, L. (Producers and Directors). (1989). Communicating across cultures. Valuing Diversity (film series). San Francisco: Copeland-Griggs Productions.

Copeland, Lennie and Griggs, Lewis. (1985) . Going international. New York: Random House Inc.

Cushman, D. and Sanderson King, S. (1985). National and organizational cultures in conflict resolution. In William Gudykunst (Ed.), Communication, culture and organizational processes. International and Intercultural Communication Annual, 9, 114-133.

Cushner, K. (1988). Achieving intercultural effectiveness. Education and Urban Society, 20(2), 159-176.

Davis, J. and Rasoon, S.A. (1988). Values research and managerial behaviors: inplications for devising culturally consistent managerial styles. Management International Review. 28(3), 11-20.

Davis, Stanley M. (1971). Comparative management. Englewood Cliffs, NJ: Prentice-Hall. 
Deal, Terence and Kennedy, Allen. (1982). Corporate cultures. Reading, MA: Addison-Wesley Publishers.

Elliot, S. (1981). Perceptions of reticence: a crosscultural investigation. Communication Yearbook 5. (pp. 591-604). New Brunswick, NJ: International Communication Association.

Ehrenhaus, P. (1983). Culture and the attribution process. International and Intercultural Communication Annual, I, (pp. 259-270).

England, G., Negandhi, A. and Wilpert, B. (1979). organizational functioning in a cross-cultural perspective. Kent, Ohio: Kent state University Press.

Fearing, Franklin. (1954). An examination of the conceptions of Benjamin Whorf in light of theories on perception and cognition. In Harry Hoijer (Ed.), Lanquage in culture. Chicago: University of Chicago Press.

Feingold, Paul C. (1976). Toward a paradigm of effective communication: an empirical study of perceived communicative effectiveness. Dissertation Abstracts International, (37) 8. Ann Arbor: University Microfilms International No. 77-1712.

Feuer, Dale. (1987, December). The skill gap: America's crisis of competence. Training, (24)12, pp. 27-36.

Frey, Lawrence T., Friedman, Paul, and Kreps, Gary, (Eds.). (1991). Investigating communication. New Jersey: Prentice Hall.

Galagan, Patricia. (1991). Tapping the power of a diverse workforce. Training and Development Journal (45) $3,38-44$.

Geber, Beverly. (1990, March). Managing diversity. Training, 27(3), pp. 23-30.

Giles, Howard and Franklyn-stokes, Arlene. (1989). Communicator characteristics. In Handbook of international and intercultural communication, (pp. 117-144). Newbury Park: Sage Publications. 
Go, Mae. (1984). Quantitative content analysis. In W. Gudykunst and Y. Kim (Eds.), Methods for intercultural communication research (pp. 147154). Beverly Hills: Sage Publications.

Goldhaber, G. (1974) . Organization communication. New York: state University of New York.

Hall, Edward. (1976). Beyond culture. Garden City, NY: Doubleday and Co.

Hannigan, T. (1990). Traits, attitudes, and skills that are related to intercultural effectiveness and their implications for cross-cultural training: a review of the literature. International Journal of Intercultural Research, 14(1), 89-112.

Harris, Philip and Moran Robert. (1979). Managing cultural differences. Houston: Gulf Publishing.

Harris, Philip and Moran, Robert. (1982) . Managing cultural synergy. Houston: Gulf Publishing.

Harrison, Robert. (1966). The design of cross-culture training. In National Education Association, Explorations in human relations training and research, 2, 4. Bethesda: National Training Laboratory.

Hayles, Robert. (1978). Costs and benefits of working with heterogeneous groups. Washington, D.C.: Office of Naval Research.

Hedlund, Gunnar. (1984). Managing relationships with foreign subsidiaries. Stockholm: Mekan Press.

Hofstede, G. (1984) . Culture's consequences: international differences in work-related values. Cross-cultural research and methodologies series, 5 . Beverly Hills: Sage Publications.

Hoopes, David. (1979). Intercultural communication concepts: the psychology of intercultural experience. In Margaret Pusch (Ed.), Multicultural education, (pp.9-38). Chicago: Intercultural Press, Inc.

Hudson Institute. (1988). Workforce 2000: executive summary. Washington, D.C.: U.S. Department of Labor. 
Huseman, Richard et al (1985). Business Communication. Chicago: The Dryden Press.

Imahori, T. and M. Lanigan. (1989). Relational model of intercultural communication competence. International Journal of Intercultural Research, $13,(3), 269-286$.

Jensen, Vernon. (1970) - Perspectives on nonverbal communication. Minneapolis: University of Minnesota.

Jensen, V. (1973). Communicative functions of silence. ETC: A Review of General Semantics, 30(3), 249257 .

Jolie, Simon. (1990, september 12). As cultural diversity of workers grows, experts urge appreciation of differences. Wall street Journal, pp. B1.

Joynt, Pat.(1985). Cross-cultural management: the cultural context of micro and macro organizational variables. In Pat Joynt and Malcolm Warner (Eds.), Managing in different cultures, (pp. 57-68). London: Universitetforlaget AS.

Kallaus, N. and Keeling, B. (1983). Administrative office management. (9th Ed.) Cincinnati: Southwestern Publishing Company.

Kanter, Rosabeth Moss. (1983) . The change masters. New York: Simon and Schuster, Inc.

Katz, K. and Kahn R. (1978). The social psychology of organizations, 2nd edition, New York: Wiley and Sons.

Kim, Young Yun. (1988). Communicaton and cross-cultural adaptation: an integrative theory. Clevedon, England: Multilingual Matters Ltd.

Klatt, L. Murdick, R. and Schuster, Fr. (1978). Human resources management. Homewood, Ill: Richard D. Irwin, Inc.

Kluckhohn, F. and Strodtbeck, F. (1961). Variations in value orientations. Evanston: Row, Peterson.

Knapp, Mark. (1972). Non-verbal communication in human interaction. New York: Holt, Rinehart, and Winston. 
Knotts, Rose. (1989, Jan.-Feb.). Cross-cultural management: transformations and adaptations. Business Horizons, (32) 1, pp. 29-33.

Kohls, Robert. (1979). Survival kit for overseas living. Yarmouth, ME: Intercultural Press.

Kras, Eva. (1988). Management in two cultures. Yarmouth, ME: Intercultural Press, Inc.

Kume, Teruyuki. (1985). Managerial attitudes toward decision-making: North America and Japan. International and intercultural communication annual, 9 , 231-251.

LaFrance, M. and Mayo, Co. (1976). Racial differences in gaze behavior during conversations: two systematic observational studies. Journal of Personality and Social Psychology, (33), 547-52.

Laurent, Andre. (1983). The cultural diversity of western conceptions of management. International studies of Management and organization, 13(1-2), 75-96.

Lewis, Phillip V. (1975) - Organizational communication: the essence of effective management. Columbus, $\mathrm{OH}$ : Grid Publishers.

Littlejohn, stephen. (1983). Theories of human communication. Belmont, $\mathrm{CA}$ : Wadsworth Publishers.

Lofland, John and Lynn. (1984). Analyzing social settings. Belmont, CA: Wadsworth Publishing Co.

Luthens, Fred. (1985). Organizational behavior (4th Ed.) New York: McGraw-Hill.

Malandro, Loretto and Barker, Larry. (1983). Nonverbal communication. Reading, MA: Addison-Wesley Publishing Co.

McCann, Eugene (1964). An aspect of management philosophy in the U.S. and Latin America. Academy of Management Journal, $7,(2)$, pp. 149-152.

McCracken, Grant. (1988) . The Long Interview. Newbury Park: Sage Publications.

Mead, Margaret. (1978) - Culture and commitment. New York: Anchor Books. 
Mehrabian, A.(1971). Silent Messages. Belmont, CA:, Wadsworth Publishing.

Miller, S.W. and Simonetto, J. (1971). Culture and management: some conceptual considerations. (Working Paper), Kent, $\mathrm{OH}$ : Kent State University.

Mondy, R. W., Sharplin, A., Gordon, J., and Premeaux, S. (1989). Management and Organizational Behavior.

Boston: Allyn and Bacon.

Nadler, Lawrence B., Marjorie K. Nadler \& Benjamin Broome. (1985). Culture and the management of conflict situations. International and Intercultural Communication Annual, $9(2), 87-113$.

Negandhi, A. (1985). Management in the third world. In Pat Joynt and Malcolm Warner (Eds.), Managing in different cultures, (pp. 69-87). London: Universitetsforlaget AS.

Nemetz-Robinson, Gail. (1985) . Cross-cultural Understanding. New York: Pergamon Press.

Nydell, Margaret. (1987) - Understanding Arabs. Yarmouth, ME: Intercultural Press.

Odiorne, George. (1987). The human side of management. San Diego: University Associates, Inc.

Owens, T. and Lindner, F. (1983). Entry level worker study. Portland: Northwest Regional Educational Laboratory.

Paige, Michael. Personal Attributes of the Cross Cultural Trainer from Training competencies: the Missing conceptual Link in orientation. International Journal of Intercultural Relations, (10)2, 135-158.

Pascale, R. and Athos, A. (1984). Great companies make meaning. In John Williamson, (Ed.), The Leader manager. New York: John Wiley and Sons.

Pedersen, Paul. (1988). Handbook for developing multicultural awareness. Alexandria, VA: American Association for Curriculum Development.

Pusch, Margaret (Ed.). (1979). Multicultural education. Chicago: Intercultural Press. 
Ramsey, Sheila. (1979). Nonverbal behavior: an intercultural perspective. In M. Asante, Newmark, \& Blake (Eds.), Handbook of Intercultural Communication (pp. 105-143). Beverly Hills, CA.: Sage Publications.

Rash, J.E. (1988). Practical perspective on intercultural understanding. Education and Urban Society, 20(2), 211-225.

Redding, w. Charles. (1972). Communication within the organization. New York: Industrial Communications council.

Rice, A. (1965). Learning for Leadership. London: Tavistock Publishers.

Richardson, Stephen, Dohrenwend, Barbara, and Klein, David. (1985). Interviewing: its forms and functions. New York: Basic Books, Inc.

Roberts, Donald.(1971). The nature of communication effects. In Scramm and Roberts (Eds.), The process and effects of mass communication (pp. 368-71). Chicago: University of Illinois Press.

Ronen, Simcha (1986). Comparative and multicultural management. New York: J. Wiley and Sons.

Samovar, Larry and Porter, Richard. (1982). Approaches to intercultural communication. In L.Samovar and R. Porter (Eds.), Intercultural communication: a reader (4th Ed.), (pp. 15-30. Belmont, CA: wadsworth. p. 27

Samovar, Larry and Porter. (1981). Understanding intercultural communication. Belmont, CA: Wadsworth Publishing.

Saville-Troike, Muriel. (1982). The ethnography of communication. Oxford: Basil Blackwell.

Schein, Edgar. (1985). organizational culture and leadership. San Francisco: Jossey-Bass.

Schnake, Mel. (1990) Human relations. Columbus, OH: Merrill Publishing.

Shimanoff, Susan. (1980). Communication rules: theories and research. Beverly Hills: Sage Publications. 
Silver, L. (1990, August 27). White males still dominate top-level jobs. The oregonian, pp. B1.

Sitaram, K.S. and Haapanen, Lawrence. (1979). The role of values in intercultural communication. In Molefi

Asante (Ed.), Handbook of Intercultural

Communication (pp. 147-160).Beverly Hills: Sage.

Spradley, James. (1979). The ethnographic interview. New York: Holt, Rhinehart and winston.

Stewart, Edward C. (1972). American cultural patterns. Yarmouth, MA: Intercultural Press.

Stewart, Edward and Bennett, Milton. (1991). American cultural patterns. Revised edition. Yarmouth, ME: Intercultural Press.

Stewart, Lea. (1972). Subjective culture and organizational decision-making. In H.C. Triandis (Ed.), The analysis of subjective culture. New York: Wiley-Interscience.

Stull, James. (1973). Demonstrating empathy for foreign -born employees through openness and acceptance: a quasi-experimental field study. Journal of communication, 23(2), 31-39.

Sypher, Beverly \& Applegate, Sypher, J. (1985). Culture and communication in organizational contexts. International and Intercultural communication Annual, 9, 13-29.

Tannebaum, R., Weschler, L., and Massarik, F. (1961). Leadership and Organization. New York: McGraw-Hill.

Taylor, Steven and Bogdan, Robert. Introduction to qualitative research methods. New York: John Wiley and Sons.

Tortoriello, T., Blatt, S., and DeWine, S. (1978). Communication in the organization. New York: McGrawHill.

Tucker, Raymond, Weaver, II, Richard and Berryman-Fink, Cynthia. (1981). Research in speech communication. Englewood Cliffs, NJ: Prentice-Hall. 
Uterhoeven, Hugo, (1990). General managers in the middle. Harvard Business Review. Article no. 89544, Harvard Business School Publishing.

Von Eron, A. (1991, May). The diverse workforce and organizational productivity. Cultural Diversity at Work, $3(4), 3$.

Watzlawick, Paul, Beavin, Janet and Jackson, Donald. (1967) . pragmatics of human communicaton. New York: Norton Publishers. 
GUI INNOILSARO

$\forall$ XIGNAddV 
APPENDIX A

QUESTIONNAIRE

Section one - Information

Please describe your job to me, i.e., what are your assigned duties as a manager?

How long have you worked in this position?

What do you see as the primary responsibilities you have toward the people you supervise?

What number of employees do you supervise?

What percentage would you describe as being non-U.S. mainstream (of white, European descent), for example, recent immigrants or refugees, Asians, Blacks, Hispanics, etc.?

How would you describe the "culture" of your organization?

-is it team-oriented or competitive on an individual basis?

-is there a company motto?

-what is the company mission or philosophy?

-what are some company rituals?

- what are some company social activities?

Communication Situations - orientation

I'd like to ask you about two types of situations during which you might have interacted with an ethnically or racially different employee: new employee orientations and giving instructions to an employee.

- Please describe how you might conduct an orientation

- what is the process (i.e., are there several steps)?

- what are its elements (for example, is there an 
overview of the company, a tour of the plant, and so on)?

- what time period does it cover (hours, days, weeks)?

- What do new employees need to know in terms of social rules, the company philosophy in order to get along at your organization?

- Are there some things you might particularly emphasize or describe to an ethnically or racially different employee?

- Please describe an orientation that, in your opinion, did not go well

- In terms of communication, what do you think were the reasons it did not go well?

- During these orientations, did you notice any stress or tension on the part of the employee or yourself? What do you think caused it?

- During these sessions did you have the sense that any misunderstanding, in term of communication, took place?

- Do you recall any behaviors on the part of the employee which you found difficult to interpret? 
- Have you experienced:

-situations where an employee say yes, he/she understands, and then exhibits behavior which indicates the opposite

-situations where the employee was silent for what seemed to be an overly long time

-situations where the eye contact of the employee seemed somehow wrong

-situations where the employee didn't seem to be listening

(if the manager answers yes to any of the above questions, the followup probe question would be "Could you describe one such situation?")

- What have you found to be useful strategies and behaviors in these situations?

Communication Situations - Giving Instructions to Employees

- Can you describe your general approach in giving instructions to employees?

- Do you modify your approach when dealing with ethnically or culturally different employees?

- Can you describe a situation in which you feel that there was either no communication or misunderstanding

- Can you describe some interesting experiences you've had in giving instructions to ethnically or culturally different employees?

- With regard to such employees, have you had the experience of :

- having an employee say yes, s/he understands and then exhibit behavior which indicates the opposite

- situations where the amount of eye contact from the employee was too much/too little

- the employee standing uncomfortably close to you

- an unusually silent employee 
- situations where the employee didn't appear to be listening

- situations where it seemed an employee took less initiative in completing the task than you preferred

- situations where it was difficult to interpret an employee's behavior?

Please describe the situation, the behavior, and your feelings about it.

- situations where it seemed less important to the employee than to you that the work was done on time (if the manager responding affirmatively to any of the above questions, he/she would again be asked to describe an example)

What have you found to be useful behaviors when dealing with the above situations?

From a general perspective, what have you found to be useful behaviors when giving instructions to an employee who was culturally or ethnically different from yourself? What have you changed (if anything) in your behaviors? 
SIINSG্স $\forall \amalg \forall O$

G XIONAddY 


\section{APPENDIX B}

DATA RESULTS

\section{COMMUNICATION ISSUES - ORIENTATION OF NEW EMPLOYEES}

Question: Can you recall orientation sessions that did not go well?

$$
\text { Manager No. } 1 \text { Manager No. } 2 \text { Manager No. } 3
$$

Response yes yes no

Question: What do you think were the reasons it did not go well?

$$
\text { Manager \#1 Manager \#2 Manager \#3 }
$$

\section{Responses}

- Language Differences-

- Employee did not seem $x$ to understand

-Mgr. couldn't understand $x \quad x$ employee

- Nonverbal Differences

-Inappropriate nonverbal x $\mathrm{x}$

behavior by employee

-other

-Information to $x \quad x$

employee too limited

-Communi. apprehension $x \quad x$

*Manager \#3 indicated that she had not encountered any communication difficulties during orientations.

\section{RESPONDING BEHAVIORS}

Question: What did you find to be useful behaviors in successfully addressing these issues? 
Response:

$$
\text { Manager \#1 Manager \#2 Manager \#3 }
$$

- exam.of

- orient.process

- commun. style

$x$

$x$

- modificat. of speech $x$ rate

- modif. of approach $x$

- modif. of facial $x$ expression

- use of interpreter $x$

- use of questioning $x$

- restating or para- $x$

- phrasing by employee

- "test" statements $x$

- repeating info. $x$

- slower speech rate $x$

- use of simpler words $x$ $x$

$x$

\section{GIVING INSTRUCTIONS TO NEW EMPLOYEES}

Question: Can you recall situations involving giving instructions to minority employees where the communication did not go well?

Response Manager \#1 Manager \#2 Manager \#3

$$
\text { yes yes yes }
$$

Question: Can you describe any situations in which you feel there was either no communication or misunderstanding?

Response:

Mgr. didn't

understand

employee

$x$

$\mathrm{x}$

$x$

Employee didn't

understand mgr. $x$

$x$ 
Inappropriate

$n$.v. behavior by

employee

$x$

$\mathbf{x}$

RESPONDING BEHAVIORS

Question: What have you found to be useful behaviors when dealing with the above situations?

Response:

$$
\text { Manager \#1 Manager \#2 Manager \#3 }
$$

Verbal

- slower speech $x$

- simpler words $x$

- elim. slang $x$

- shorter senten. $x$

- repetition $x$

- rephrasing $x$

- asked for paraphrasing $x$

- asked questions $x$

- asks for input

- improves listen.

- asks for more information

- used test questions

- used interpret. $x$

$\begin{array}{lll}x & x \\ x & & \\ x & & \\ x & x & \\ x & & \\ x & x & x \\ & & x \\ & x & x \\ & x & x\end{array}$




\begin{abstract}
APPENDIX C
COMMUNICATION ISSUES AND EFFECTIVE BEHAVIORS:

RESULTS OF LITERATURE SEARCH
\end{abstract}




\author{
APPENDIX C \\ COMMUNICATION ISSUES AND EFFECTIVE BEHAVIORS: \\ RESULTS OF LITERATURE SEARCH
}

Communication Issues

Differing perceptions

Differences in meaning

Language differences

Different communication rules

Different patterns of thinking

Different styles of decisionmaking

Different values

Nonverbal differences

Stereotyping

Attribution

Effective Behaviors

openness

Ability to listen effectively

Ability to give useful feedback

Tolerance of ambiguity

Flexibility

Nonjudgmentalness

Awareness of difference

Self awareness

Valuing of diversity 